\title{
AC Processing Controllers for IPT Systems
}

\author{
Hunter Hanzhuo $\mathrm{Wu}^{1}$, Grant Anthony Covic ${ }^{2}$ and John Talbot Boys ${ }^{2}$ \\ ${ }^{1}$ Energy Dynamics Laboratory, Utah State University Research Foundation \\ ${ }^{2}$ Department of Electrical and Computer Engineering, The University of Auckland \\ ${ }^{1}$ USA \\ ${ }^{2}$ New Zealand
}

\section{Introduction}

Inductive Power Transfer (IPT) systems allow electrical energy to be transferred over a relatively large air gap via high frequency magnetic fields. Such systems can be broadly classified based on application, but all such systems have various key components that include; the power electronic transmitter, the receiver electronics, the magnetic coupler and the power flow controller. The purpose of using a power flow controller is to regulate the power delivered to a load using a reference independent of system parameter variations of the IPT system. Some of the common parameters which can cause variations in the power transfer of an IPT system are load resistance and coupling coefficient. Recently, a new type of power controller called an AC processing pickup has been proposed with significant advantages in terms of increasing system efficiency, reducing pickup size and lowering production cost compared to traditional pickups that also produce a controlled AC output using complex AC-DC-AC conversion circuits. This new controller is in two forms but both forms regulate AC power directly and produce a controllable high-frequency AC source over a wide load range suitable for lighting and EV charging applications. This chapter outlines the details and operation of the two different types of AC processing pickups along with analytic analysis. Simplified design examples with practical implementation methods will be presented for systems with variations in load and coupling.

\section{Parallel AC processing pickups}

A parallel AC processing pickup capable of producing an AC controllable current source is described below.

\subsection{Fundamentals of the AC processing pickup}

A schematic circuit for a parallel AC processing pickup coupled to a resonant IPT track is shown in Fig. 1. The primary track is assumed to be energised using a resonant supply which operates at fixed frequency and adjusted to keep the track current $I_{1}$ nominally constant independent of load. Capacitor $C_{2}$ is tuned to pickup inductor $L_{2}$ at the frequency of this primary track current $I_{1}$ to form a resonant tank. The diodes $\left(D_{1}, D_{2}\right)$ and switches $\left(S_{1}\right.$, $S_{2}$ ) form an AC switch. From standard IPT theory, a pickup coil placed in the vicinity of the primary track would have an open circuit voltage $\left(V_{o c}\right)$ source induced within it that is given by: 


$$
V_{o c}=j \omega M I_{1}
$$

where $\omega$ is the operating angular frequency, $M$ is the mutual inductance and $I_{1}$ is the primary track current.

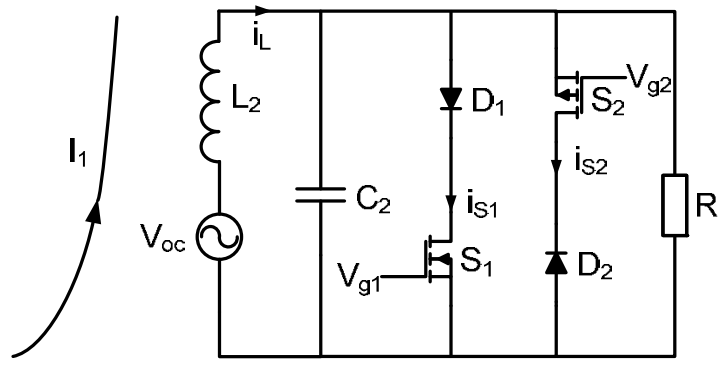

Fig. 1. The parallel AC Processing Pickup.

To illustrate the circuit operation, Fig. 2 shows the waveforms when the switches are used to clamp parts of the resonant capacitor voltage. $V_{g^{1}}$ and $V_{g^{2}}$ are the PWM gate signals used to drive switches $S_{1}$ and $S_{2}$ at $50 \%$ duty cycle with the same switching frequency as the IPT track frequency. Consider the situation where waveforms $V_{g^{1}}$ and $V_{g^{2}}$ are controlled with a phase delay $\phi$ relative to the phase of $V_{\text {oc }}$ as shown in Fig. 2. At time $t=0, S_{1}$ is turned off and $S_{2}$ is turned on. However, the series diode $D_{2}$ blocks any current flowing through $S_{2}$ as it is reverse biased. This causes the capacitor $C_{2}$ to resonate with the pickup inductance $L_{2}$ like a parallel resonant tank. The capacitor voltage rings to a peak value and returns back to zero.

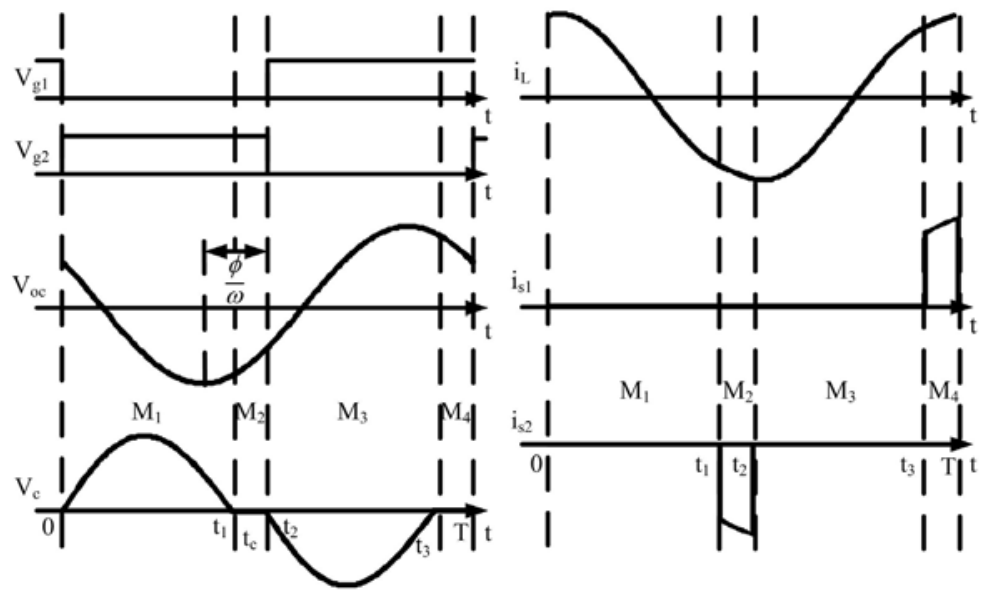

Fig. 2. Typical Single Cycle Operating Waveforms when the Switches Clamp the Resonant Capacitor Voltage for the Parallel AC Processing Pickup.

When the capacitor voltage reaches zero, $D_{2}$ terminates the resonant cycle and prevents the capacitor voltage building up in the negative direction as it begins to conduct at zero volts, thereby clamping the output voltage to zero. This causes $S_{2}$ to clamp $V_{c}$ for a time known as 
the clamp time $\left(t_{c}\right)$ at the point where $V_{c}$ changes from a positive to a negative voltage. In summary, the clamping action from the AC switch generates a phase shift between the open circuit voltage and the capacitor voltage waveform. A single cycle operation for the AC processing pickup is composed of a sequence of linear circuit stages with each corresponding to a particular switching interval as illustrated to Fig. 3. These can be grouped into the following modes:

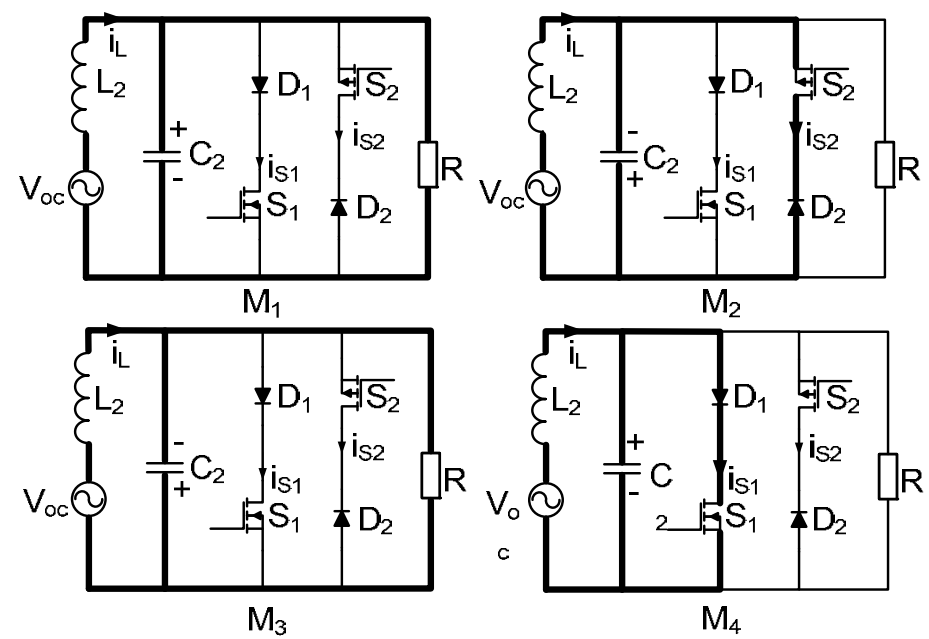

Fig. 3. Operating Modes of the Parallel AC Processing Pickup.

Mode $1\left(M_{1}\right)$ : At $t=0, S_{1}$ is turned off and $S_{2}$ is turned on. The capacitor voltage $V_{c}$ will resonate with the pickup inductor to a positive peak voltage and then decay. Since $D_{2}$ is reversed biased due to positive $V_{c}$, it blocks any current that flows through $S_{2}$. Under this mode, the circuit operates like a parallel resonant tank and current flows into the load resistor.

Mode $2\left(M_{2}\right)$ : At $t=t_{1}$, the capacitor voltage naturally crosses zero. Since $S_{2}$ is still turned on, $D_{2}$ becomes forward biased, the resonant cycle is terminated and the capacitor voltage is clamped. In this mode, the inductor current flows through switch $S_{2}$ and no current flows through the load.

Mode $3\left(M_{3}\right)$ : At $t=t_{2}, S_{1}$ is turned on and $S_{2}$ is turned off. Similar to $M_{1}$, the circuit operates like a parallel resonant tank and current flows into the load resistor.

Mode $4\left(M_{4}\right)$ : At $t=t_{3}$, the capacitor voltage naturally crosses zero. Similar to $M_{3}$, the resonant cycle is terminated and the capacitor voltage is clamped. In this mode, the inductor current flows through switch $S_{1}$ and no current flows through the load. After this mode, the circuit returns back to $M_{1}$, and the switching process is repeated.

The AC processing pickup achieves approximate soft switching conditions. From Fig. 3, the resonant inductor current starts to flow through $S_{2}$ at $t_{1}$ when there is no voltage across it, hence ZVS is achieved at turn on. When $S_{2}$ is turned off at $t_{2}$, the resonant capacitor in parallel with $S_{2}$ forces the voltage across $S_{2}$ to increase slowly in the negative direction while the current through it decreases to zero. For most practical switches, the turn off is much faster than the rate of increase of the capacitor voltage, so the $\mathrm{dv} / \mathrm{dt}$ across the switch is 
relatively small and ZVS is obtained at the switch off condition. Switch $S_{1}$ operates in a similar manner and also achieves ZVS at turn on, while achieving a low $\mathrm{dv} / \mathrm{dt}$ at turn off. Likewise, for diodes $D_{1}$ and $D_{2}$, low dv/dt is achieved at turn on, and ZVS is achieved at turn off. In summary, the switches and diodes in the AC processing pickup achieve soft switching. This gives the pickup desirable characteristics such as low switching losses, low switching stress and reduced electromagnetic interference (EMI) levels. The low switching losses gives this pickup controller a very high operating efficiency. Moreover, the low EMI provides little interference on the control circuitry of the pickup and external systems nearby.

\subsection{Exact analysis of the parallel AC processing pickup}

It has been shown in (Wu et al., 2009a) that the AC processing controller regulates the output power by controlling phase delay. In this section, an exact analysis in the time domain is proposed to determine the characteristics of the circuit under steady state operation. The basis of the analysis method is that the conditions existing in the circuit at the end of a particular switching period must be the initial conditions for the start of the next switching period, and these conditions must be identical, allowing for changes in polarity caused by the resonant operation.

The analysis procedure is simplified using the same assumptions:

1. The Equivalent Series Resistance (ESR) of both capacitor $C_{2}$ and Inductor $L_{2}$ are very small and can be neglected.

2. The switching action of the transistors and diodes are instantaneous and lossless.

\subsubsection{Basic equations}

Let the tuning capacitance of the circuit be,

$$
C_{2}=a C_{20}
$$

where

$$
C_{20}=1 /\left(\omega^{2} L_{2}\right) \quad a \in|R|
$$

With reference to Fig. 4, the waveform can be separated into two operating modes known as the resonant mode and the clamp mode.

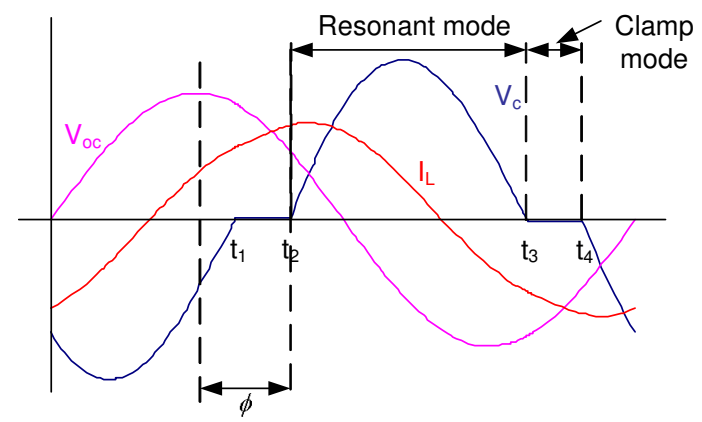

Fig. 4. Waveform in Two Modes for the Parallel AC Processing Pickup. 


\subsubsection{Resonant mode}

During the resonant mode, the capacitor voltage may be described as:

$$
\frac{d^{2} V_{c}}{d t^{2}}+\frac{1}{R C_{2}} \frac{d V_{c}}{d t}+\frac{V_{c}}{L_{2} C_{2}}=\frac{V_{o c}}{L_{2} C_{2}} \sin (\omega t+\phi)
$$

Considering the initial condition $\left.V_{c}(t)\right|_{t=0}=0$ and $\left.\frac{d V_{c}}{d t}\right|_{t=0}=\frac{-i_{L}(0)}{C_{2}}$, the complete solution of the above equation is:

$$
V_{c}(t)=V_{c d}(t)+V_{c u}(t)
$$

where

$$
\begin{gathered}
V_{c d}(t)=\frac{\partial_{2}}{\sin \left(\gamma_{v}\right)} e^{-\sigma t} \sin \left(\omega_{f} t-\theta_{v}\right) \\
V_{c u}(t)=(1-a) \partial_{1} \sin (\omega t+\phi)-\frac{\partial_{1}}{Q_{20}} \cos (\omega t+\phi) \\
Q_{20}=R_{2} /\left(\omega L_{2}\right) \\
\sigma=1 / 2 a R_{2} C_{20} \\
\omega_{f}=\omega \sqrt{1 / a-1 /\left(4 a^{2} Q_{20}{ }^{2}\right)} \\
\partial_{1}=V_{o c} /\left((1-a)^{2}+\left(1 / Q_{20}\right)^{2}\right) \\
\partial_{2}=\partial_{1}\left((1-a) \sin (\phi)-\cos (\phi) / Q_{20}\right) \\
\partial_{3}=\partial_{1}\left((1-a) \cos (\phi)+\sin (\phi) / Q_{20}\right) \\
\gamma_{v}=\tan ^{-1}\left(\frac{-\omega_{f} \partial_{2}}{i_{L}(0) / Q_{20}+\sigma \partial_{2}+\omega \partial_{3}}\right)
\end{gathered}
$$

In a similar way, considering the initial condition $\left.i_{L}(t)\right|_{t=0}=i_{L}(0)$ and $\left.\frac{d i_{L}}{d t}\right|_{t=0}=\frac{-V_{o c} \sin \phi}{L_{2}}$, the complete solution to the inductor current is:

$$
i_{L}(t)=i_{L d}(t)+i_{L u}(t)
$$

where

$$
i_{L d}(t)=\frac{-i_{L}(0)-\beta_{2}}{\sin \left(\gamma_{i}\right)} e^{-\sigma t} \sin \left(\omega_{f} t-\theta_{i}\right)
$$




$$
\begin{gathered}
i_{L u}(t)=\frac{-\partial_{1}}{R_{2}} \sin (\omega t+\phi)+\frac{\partial_{1} Q_{20}}{R_{2}}\left(-a(1-a)+\frac{1}{Q_{20}{ }^{2}}\right) \cos (\omega t+\phi) \\
\beta_{2}=\frac{\partial_{1}}{R_{2}}\left(\sin (\phi)-Q_{20} \cos (\phi)\left(-a(1-a)+\frac{1}{Q_{20}{ }^{2}}\right)\right) \\
\gamma_{i}=\tan ^{-1}\left(\frac{-\omega_{f}\left(i_{L}(0)+\beta_{2}\right)}{-V_{o c} \sin (\phi) / L_{2}+\omega \beta_{3}+\sigma\left(i_{L}(0)+\beta_{2}\right)}\right) \\
\beta_{3}=\frac{\partial_{1}}{R_{2}}\left(\cos (\phi)+Q_{20} \sin (\phi)\left(-a(1-a)+\frac{1}{Q_{20}{ }^{2}}\right)\right)
\end{gathered}
$$

To investigate how long the circuit stays in the resonant mode, $V_{c}=0$ can be substituted in (5), resulting in the following expression:

$$
V_{c}\left(t_{r}\right)=0
$$

where $t_{r}$ is the time the circuit operates in the resonant mode.

\subsubsection{Clamp mode}

During the clamp mode, the inductor $L_{2}$ is shorted and the current depends on $V_{o c}$. By Kirchhoff's Voltage Law, the inductor current equation can now be written as:

$$
i_{L}(t)=-\frac{V_{o c}}{L} \int_{t_{r}}^{t} \sin (\omega t+\phi) d t+i_{L}\left(t_{r}\right)
$$

Solving (22), the inductor current can be expressed as:

$$
i_{L}(t)=\left(V_{o c} \cos (\omega t+\phi)\right) /\left(\omega L_{2}\right)+i_{L}\left(t_{r}\right)-\left(V_{o c} \cos \left(\omega t_{r}+\phi\right)\right) /\left(\omega L_{2}\right)
$$

Because both the resonant mode and the clamp mode are repeated each half cycle (with only a polarity change), the relationship $i_{L}(0)=-i_{L}(T / 2)$ must hold. Hence, the capacitor voltage and inductor current must be given by,

$$
\begin{aligned}
& V_{c}(t)=\left\{\begin{array}{cc}
V_{c d}(t)+V_{c u}(t) & t_{0} \leq t<t_{1} \\
0 & t_{1} \leq t<t_{2} \\
-V_{c d}(t)-V_{c u}(t) & t_{2} \leq t<t_{3} \\
0 & t_{3} \leq t<t_{4}
\end{array}\right. \\
& i_{L}(t)=\left\{\begin{array}{cl}
i_{L d}(t)+i_{L u}(t) & t_{0} \leq t<t_{1} \\
\left(V_{o c} \cos (\omega t+\phi)\right) /\left(\omega L_{2}\right)+i_{L}{ }^{-} & t_{1} \leq t<t_{2} \\
-i_{L d}(t)-i_{L u}(t) & t_{2} \leq t<t_{3} \\
-\left(V_{o c} \cos (\omega t+\phi)\right) /\left(\omega L_{2}\right)-i_{L}{ }^{-} & t_{3} \leq t<t_{4}
\end{array}\right.
\end{aligned}
$$




\subsubsection{Computation routine}

The above analysis is very difficult to solve analytically as the solution of $t_{r}$ and $i_{L}(0)$ are governed by (24) and (25) with $\gamma_{v}$ and $\gamma_{i}$ as interim variables which are associated with the auxiliary equations (14) and (19). This is in the form of transcendental equations and it can only be solved using numeric solvers such as MATLAB or EXCEL. A computer program based on an iterative computation, shown in Fig. 5, has been developed to undertake the analysis. The program starts by initializing the circuit parameters such as $L_{2}, C_{2}$ and $R_{2}$. The initial condition of the inductor current is first set to the solution given by (5) and (15) in the routine as an educated guess. With $i_{L}(0)$ known, $t_{r}$ can be calculated solving (21) and the inductor current when the resonant mode ends can be calculated using (15). With $t_{r}$ known, the inductor current after half a period can be calculated using (23). The next step is to check whether $i_{L}(0)$ and $-i_{L}(T / 2)$ have converged to within a given error $(\varepsilon<0.01 \%)$. If the answer is YES, the program terminates and the correct solution is deemed to be found. Otherwise the iteration repeats itself in the computation loop until a solution is found. The algorithm has proven to be both fast and robust.

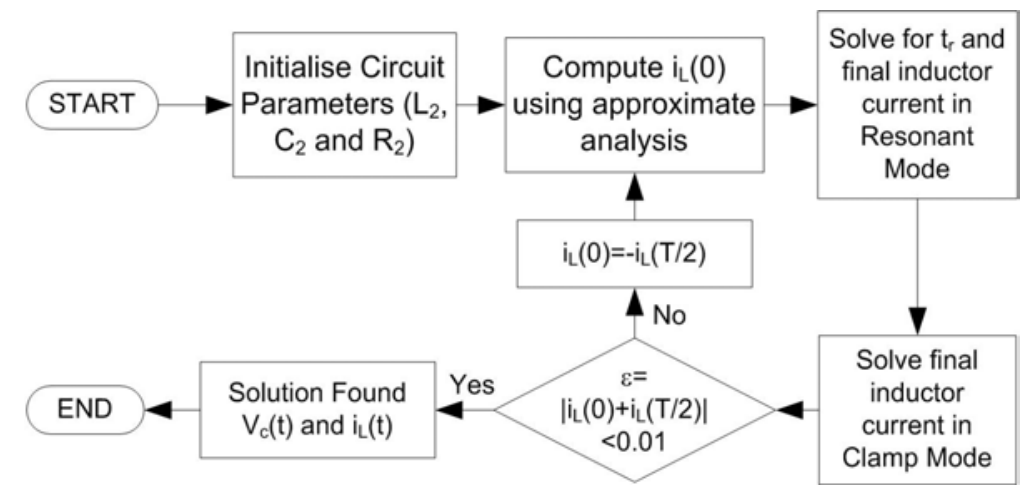

Fig. 5. A Flow Chart of Computation Algorithm.

\subsubsection{Pickup characteristics}

Using the exact analysis method proposed from section 2.2.1 to 2.2.3, the normalized pickup characteristics are computed. The output voltage (or capacitor voltage) characteristics of the pickup are shown in Fig. 6(a) for different values of $Q_{20}$ or load condition. The normalized output voltage is defined by the ratio of the output voltage over the open circuit voltage. It can be seen that the output power asymptotically decreases as the controlled phase delay $\phi$ increases from zero. It should be noted that the output voltage can be controlled from the maximum permissible value of the parallel resonant tank $\left(Q_{20} V_{o c}\right)$ down to zero. The normalized output current is shown in Fig. 6(b) for a range of $Q_{20}$ values. Fig. 6(b) shows that the output current stays approximately constant as the load resistance changes for pickups at high $Q_{20}$ (5-10). As such, the parallel AC processing pickup demonstrates controllable current source behaviour.

The output current-voltage characteristic is shown in Fig. 7(a). The current source behaviour is again demonstrated as the output current stays approximately constant for a given phase delay irrespective of output voltage as long as the output voltage is reasonably high. 

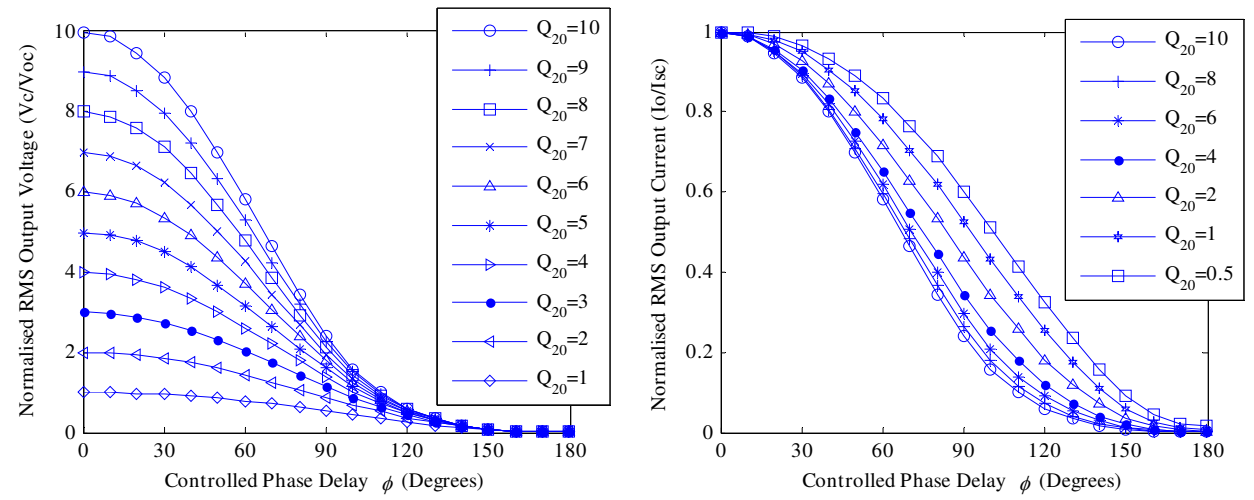

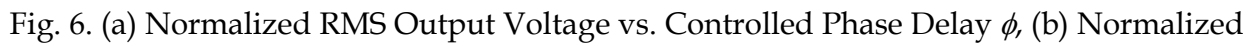
RMS Output Current vs. Controlled Phase Delay $\phi$.
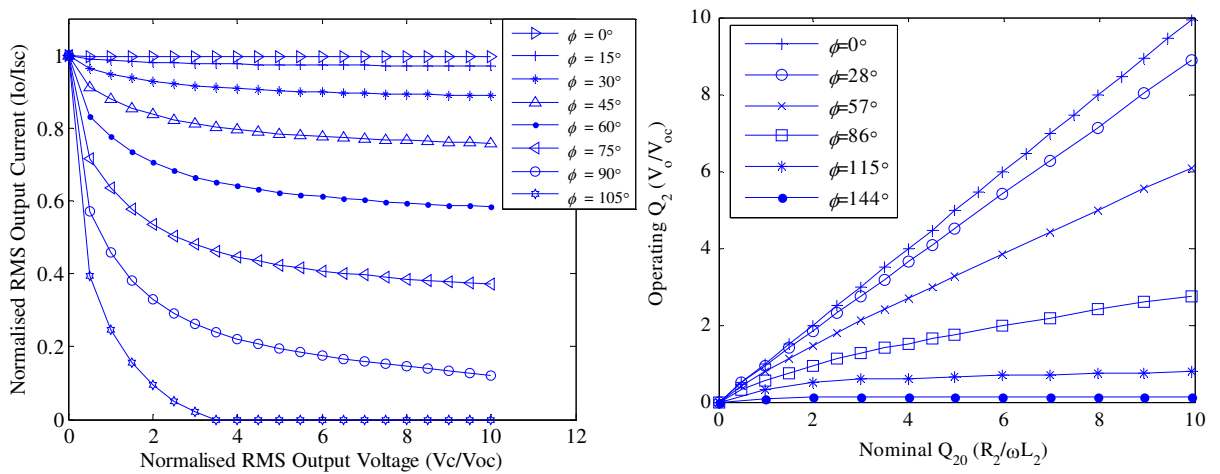

Fig. 7. (a) Pickup Output Voltage Current Characteristics, (b) Operating $\mathrm{Q}_{2}$ vs. Nominal $\mathrm{Q}_{20}$.

A plot of the secondary circuit's operating $Q_{2}$ versus its nominal operating $Q_{20}$ is shown Fig. 7(b). The current source behaviour is again demonstrated as the slope of output voltage stays constant as the nominal $\mathrm{Q}_{20}$ increases for a given phase delay.

The normalized reflected resistance and reactance are shown in Fig. 8(a) and Fig. 8(b), respectively. The normalization is performed with respect to $Z_{t}$ given by:

$$
Z_{t}=\frac{\omega M^{2}}{L_{2}}
$$

It has been found that the maximum impedance (including both its resistance and reactance) does not reach the peak when the converter is delivering full power at low $Q_{20}$ (Wu et al., 2010). The maximum reflected impedance is actually $40 \%$ higher than the value of the $Q_{20}$ of the circuit. This shows that if the secondary pickup requires power proportional to $Q_{20}$, the power supply has to source more than the real required power. However, for pickups with a $Q_{20}$ above 3 it was found that the overrating of the normalized impedance of the primary 
converter is less than $10 \%$ (Wu et al., 2010). Most commercial systems use IPT pickups with the highest $Q_{20}$ obtainable $\left(Q_{20}=3-10\right)$ to minimise the primary track current required. Under these conditions, the overrating required by the power supply is insignificant.

Fig. 9(a) shows the transient response of the AC processing pickup with a step in the controlled phase $\phi$ from $20-50^{\circ}$ at time equal to $0.5 \mathrm{~ms}$. Similarly, Fig. 9 (b) shows the transient response of the AC processing pickup with a step in the controlled phase $\phi$ from $50-20^{\circ}$ at time equal to $0.5 \mathrm{~ms}$. Simulation results using a fundamental mode analysis discussed in (Wu et al., 2010) are also added to the same figure for comparison purposes. Since such a simplified transient analysis only models the fundamental component, the peaks of the capacitor voltage calculated using (Wu et al., 2010) will be slightly less than the simulation results of the actual circuit. Nonetheless, this first order approximation can be used to provide a good rule of thumb for the capacitor voltage under transient operation. It can be seen that the transient response of the pickup is always over damped with no overshoot or undershoot, so the components in the pickup only have to be rated for steady state operation.
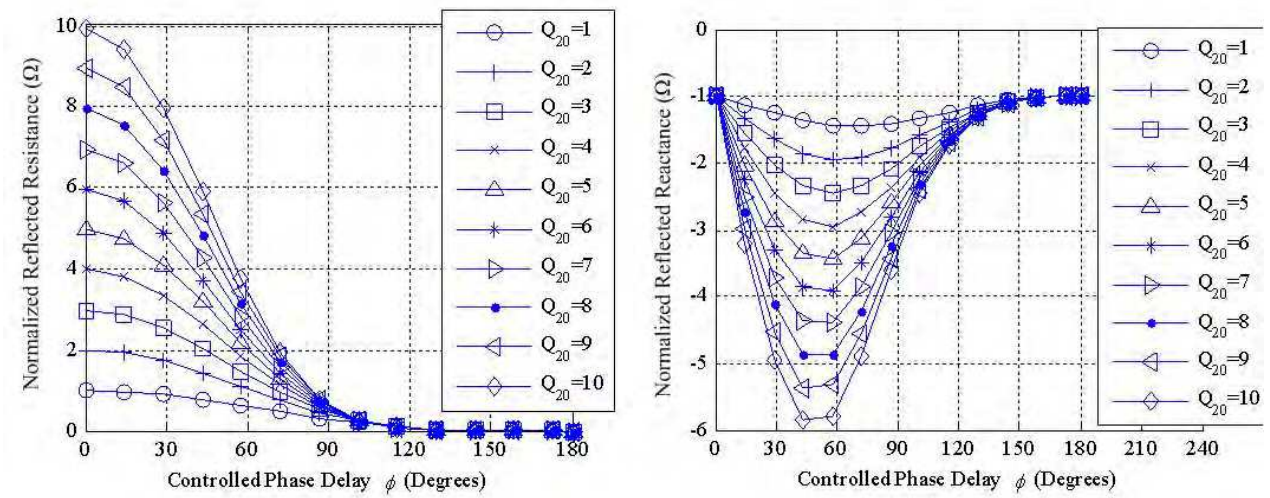

Fig. 8. (a) Reflected Resistance on Primary Track, (b) Reflected Reactance on Primary Track.
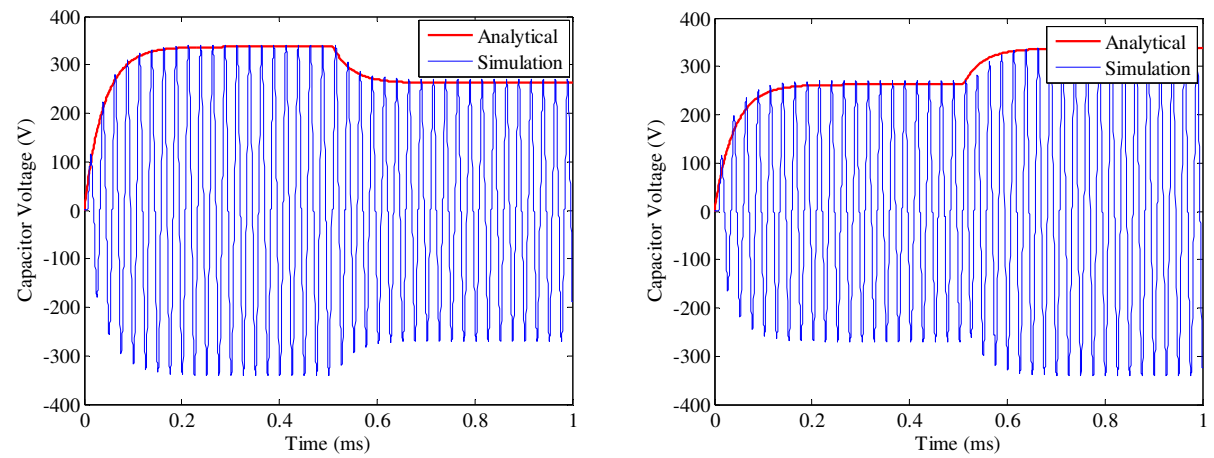

Fig. 9. (a) Capacitor Voltage when Controlled Phase Delay $\phi$ Steps from $20-50^{\circ}$, (b) Capacitor Voltage when Controlled Phase Delay $\phi$ Steps from 50-20. 


\subsection{Lighting applications using the parallel AC processing pickup}

Stage lighting systems have a tedious setup procedure involving many cables and plugs all connecting to the inverters below the scaffold. In addition such stage lights are usually constrained as to the position where they can be placed and any movement is severely limited due to the cables. The contactless nature of IPT enables IPT powered stage lights to be placed anywhere along a suitably installed track. Moreover, such a system can provide power to moving trolleys that could be used to carry lights, thereby providing extra flexibility for the stage lighting system.

Presently, most IPT systems produce a controlled DC output for industrial loads. In these applications, the most common secondary pickup controller rectifies the AC power, which is then regulated using a DC shorting (decoupling) switch. Such a pickup controller has the advantage of simple control circuitry and the ability to operate over a wide load range (Boys et al. 2000). The detailed operation of the pickup controller can be found in (Boys et al., 2000). In order to power high frequency AC loads such as fluorescent lights or stage lights, an extra resonant converter or DC-AC PWM inverter is required to produce a controllable AC source. One method of achieving this is to simply cascade the IPT pickup controller with a push-pull converter as shown in Fig. 10. However, the addition of a second converter is not ideal because of the large number of components required which increase cost. In addition, the two stage conversion process has losses in each stage which reduce efficiency. Likewise, a DC-AC PWM inverter also has a high component count and even more switching losses than the resonant converter due to a hard switching operation at these high frequencies.

In this section, the use of an AC processing pickup controller to produce a controllable AC power source over a wide resistive load range is presented. It uses a single conversion stage and improves the efficiency, economics and weight of the system. The pickup is used as a light dimmer to control the power delivered to a stage light while achieving high frequency soft switching conditions, contactless energy transmission, electric isolation and high efficiency.

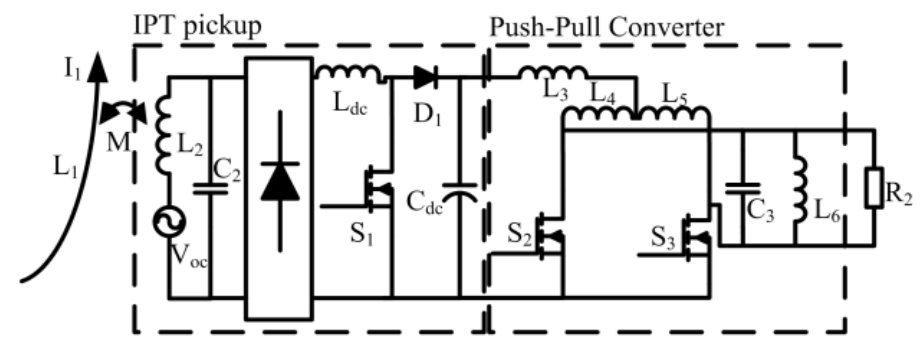

Fig. 10. An AC-DC-AC Conversion Topology.

\subsubsection{Circuit description}

A design of a $1.2 \mathrm{~kW}$ AC processing pickup used in stage lighting applications is outlined in this section. A block diagram of the lighting system is shown in Fig. 11. The switch current detection method is shown in Fig. 12. When the circuit enters the clamp state, the body diodes immediately start to conduct the resonant pickup current. Detecting this change allows the start of the clamp state to be precisely determined. A current transformer (CT) can be used to detect the switch current and transform this into a voltage signal with lower amplitude. A comparator is used to generate a $50 \%$ duty cycle square wave which may be used for the 
microcontroller to show when the circuit entered the clamped state as shown in Fig. 12. Because this technique measures the high current through the switch, it is less prone to noise. The RMS lamp voltage is first rectified (as shown in Fig. 11) and then filtered to DC inside the microcontroller. Next, the microcontroller samples this DC voltage using an ADC and adjusts the phase of the gate drive waveforms for the AC switch accordingly. The design specifications and system parameters are shown in Table 1. A primary LCL power supply is used operating at $20 \mathrm{kHz}$ and producing a track current of $125 \mathrm{~A}$. An asymmetrical shaped $\mathrm{S}$ pickup (Elliot et al, 2006) is used with an open circuit voltage of $84.9 \mathrm{~V}$ and a short circuit current of 5.86A. The tuning capacitor is chosen lower than the nominal value of (3) with an $a$ value of 0.9 (using (2)) for the reasons outlined in ( $\mathrm{Wu}$, et al., 2009b). The equivalent resistance of the Phillips Broadway $1.2 \mathrm{~kW} 220 \mathrm{~V}$ lamp changes from $3-40 \Omega$ over the full output current range. This is because the halogen bulb resistance is temperature dependent and the current flowing through it directly determines its temperature.

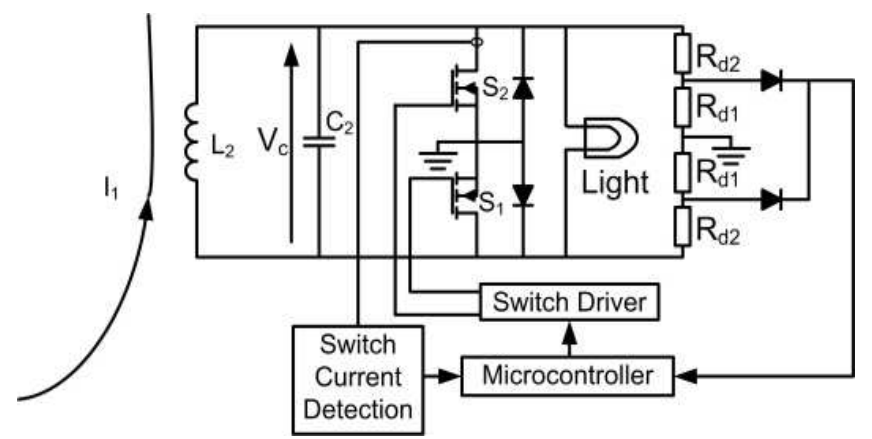

Fig. 11. Block Diagram of 1.2kW Lighting System.

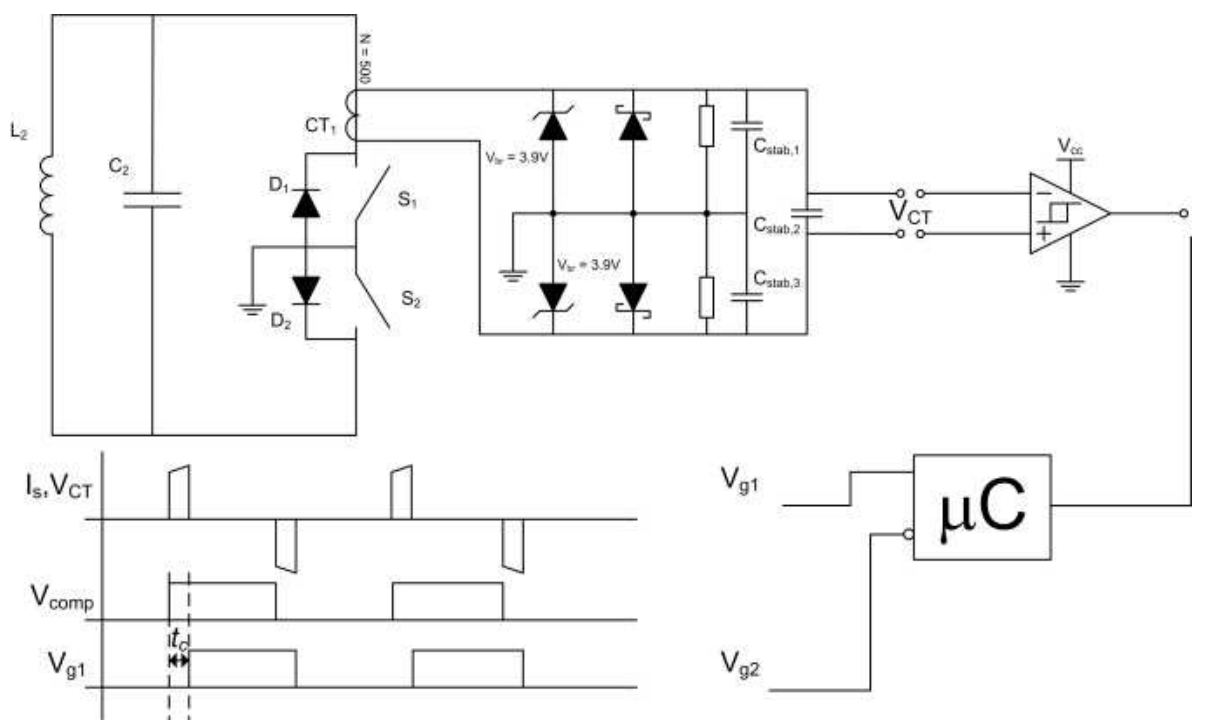

Fig. 12. Switch Current Detection. 


\begin{tabular}{|l|l|l|l|}
\hline Specification Parameters & Values & Design Parameters & Values \\
\hline$I_{1}$ & $125 \mathrm{~A}$ & $L_{2}$ & $115.2 \mathrm{uH}$ \\
\hline$P_{\text {out }}$ & $1.2 \mathrm{~kW}$ & $V_{o c}$ & $84.9 \mathrm{~V}$ \\
\hline$\left(V_{c}\right)_{r m s}$ & $220 \mathrm{~V}$ & $I_{s c}$ & $5.86 \mathrm{~A}$ \\
\hline$R_{2}$ & $3 \Omega-40 \Omega$ & $a$ & 0.9 \\
\hline$f$ & $20 \mathrm{kHz}$ & $C_{2}$ & $495 \mathrm{nF}$ \\
\hline
\end{tabular}

Table 1. Specifications and System Parameters.

For the lighting system, clamp time is used as a key parameter to control the phase delay, which then controls the output power (Wu et al., 2011a). From Fig. 13, it can be seen that the majority of the output voltage range can be achieved by using a clamp time range of 2.7$15 \mu$ s. A clamp time that is lower than $2.7 \mu$ s will result in higher output voltages than the rated voltage of the lamp and these characteristics are not measured.

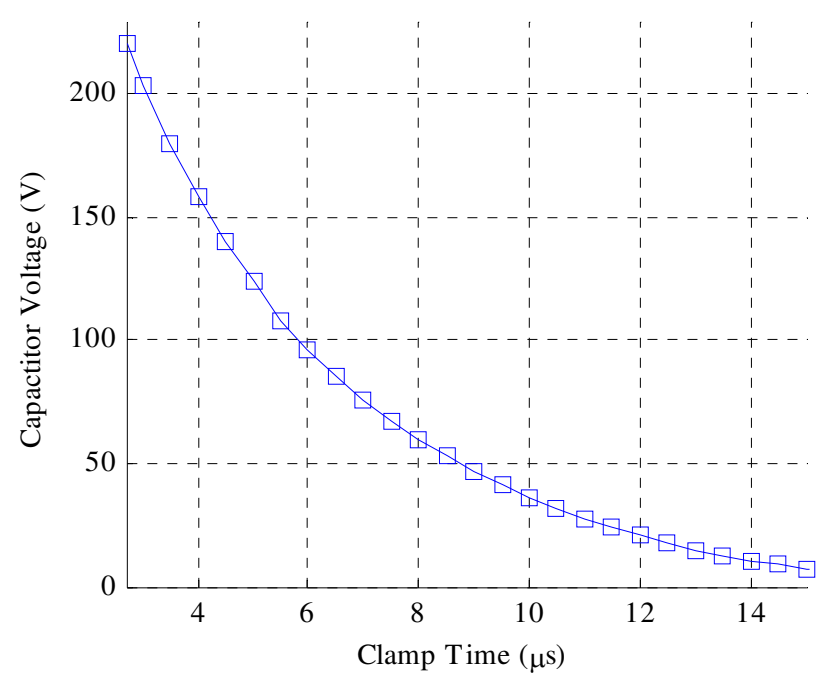

Fig. 13. Output Voltage vs. Clamp Time.

A more detailed block diagram of the microcontroller is shown in Fig. 14. As shown, a PSOC29466 microprocessor is used for the controller, as it has both analogue and digital blocks that are suited to real time control at the frequencies considered here. A second order low-pass filter with a cut off frequency of $2 \mathrm{kHz}$ is used to remove the high frequency components of the rectified output voltage. The cut off frequency should be chosen as high as possible to allow fast response of the system without compromising the filtering action to remove the $40 \mathrm{kHz}$ component and its harmonics produced by the rectifier. The filtered output is sampled at 3.2kilo-samples per second (ksps) which is the maximum the PSOC29466 can handle for this application. This is then compared against the reference set by the user. Note that aliasing is not a big concern as the input to the ADC is slow varying DC. A simple PI controller is implemented with "anti-windup". The output of the PI controller will drive the phase modulation block which generates the gate drive signals for the AC switch. 


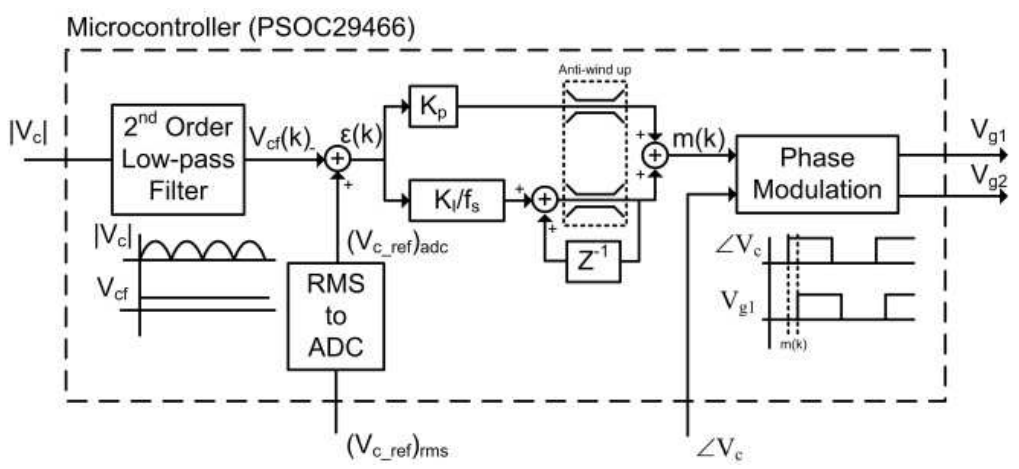

Fig. 14. Block Diagram of Microcontroller.

\subsubsection{Experimental results}

Fig. 15 shows the circuit waveforms when the output voltage is regulated to $220 \mathrm{~V}, 140 \mathrm{~V}$ and $50 \mathrm{~V}$ respectively. These correspond to $100 \%, 50 \%$ and $10 \%$ of rated power. The waveforms show the resonant capacitor voltages or output voltages (upper trace) and the pickup inductor currents (lower trace).

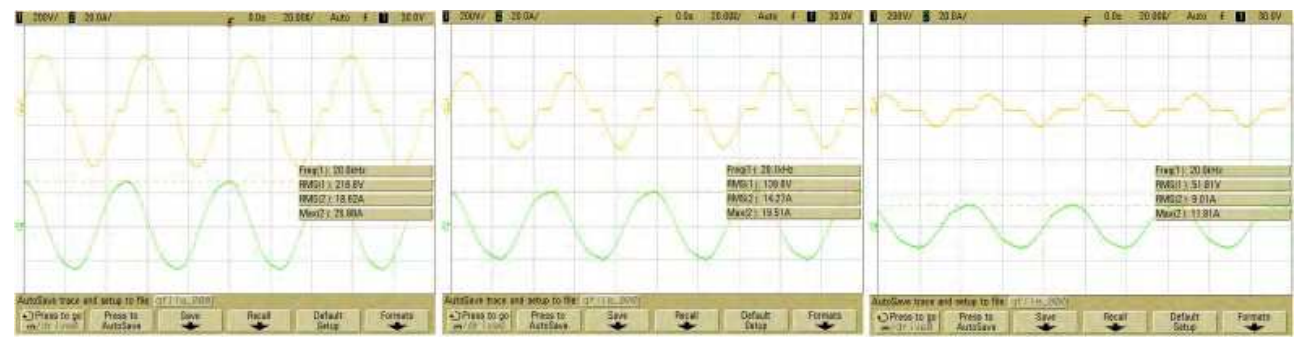

Fig. 15. Operating Waveforms of Lighting System for (a) 100\%, (b) 50\% and (c) $10 \%$ Output Power.

The transient response of the lighting system was quantified to be a simple first order system in (Wu et al., 2011a). Fig. 16(a) shows the step response of the output voltage from $30 \mathrm{~V}-220 \mathrm{~V}$. The top trace represents the lamp voltage and the bottom trace represents the lamp current. The controller is set with a PI gain of $K_{p}=1, K_{I}=375$ and an anti-windup limit of 2.7us clamp time. It can be seen that the rise time for the output current is $178 \mathrm{~ms}$ and the rise time for the output voltage is $668 \mathrm{~ms}$. Because the bulb is a non-linear resistor that changes with temperature, the output voltage and current response times are not the same. Fig. 16(b) shows the fall time for the output current and voltage, and the response times are $424 \mathrm{~ms}$ and $570 \mathrm{~ms}$.

The output current step response is largely dominated by the parallel AC processing pickup controller because of its controlled current source property. The slow response time for the output voltage is caused by the low dynamic resistance (or $\mathrm{dR} / \mathrm{dt}$ ) of the bulb which significantly slows down the transient response. The low dynamic resistance of the bulb adds an extra $490 \mathrm{~ms}$ (or more than $200 \%$ ) to the response time. In order to overcome this issue, more current can be driven into the light so that it heats up more quickly. This can be 

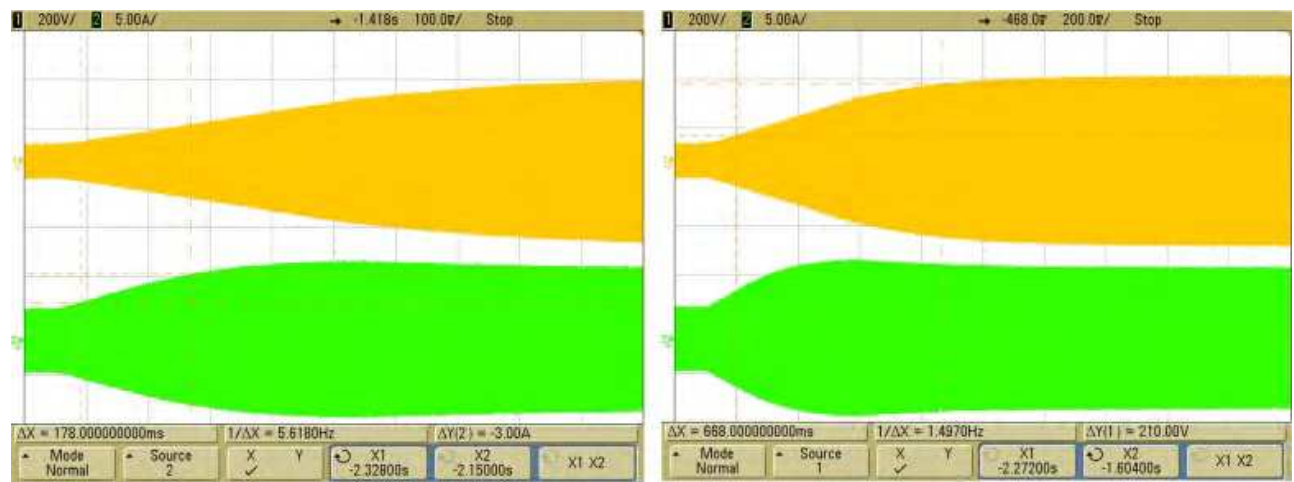

Fig. 16. 30V - 220V Step Response, $\mathrm{K}_{\mathrm{p}}=1, \mathrm{~K}_{\mathrm{I}}=375$, tc_min=2.7us showing Rise Time of (a) Bulb Current and (b) Bulb Voltage.
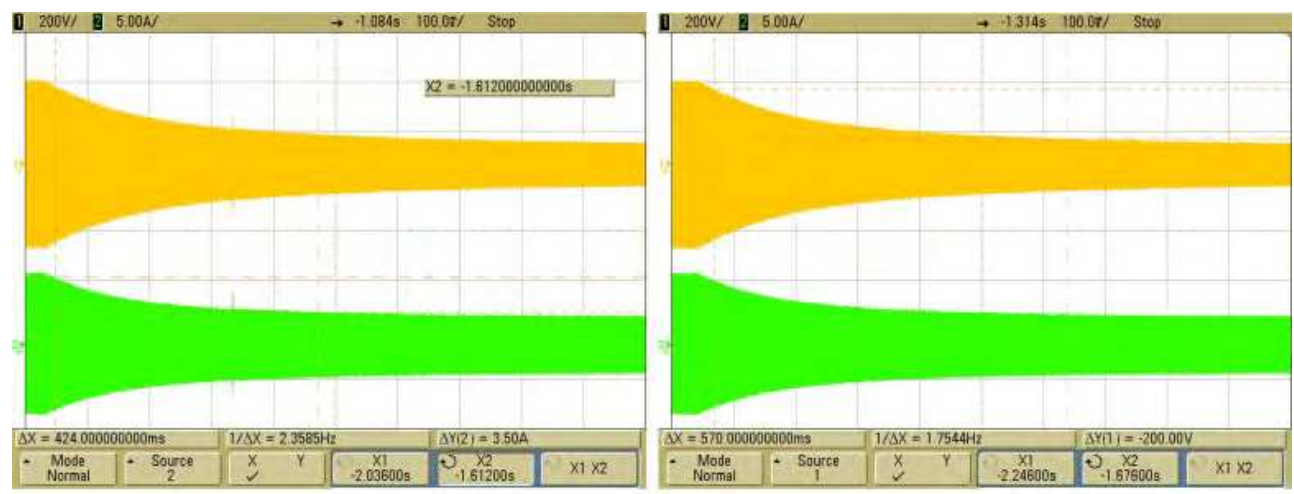

Fig. 17. 220V - 30V Step Response, $\mathrm{K}_{\mathrm{p}}=1, \mathrm{~K}_{\mathrm{I}}=375$, tc_min=2.7us showing Fall Time of (a) Bulb Current and (b) Bulb Voltage.
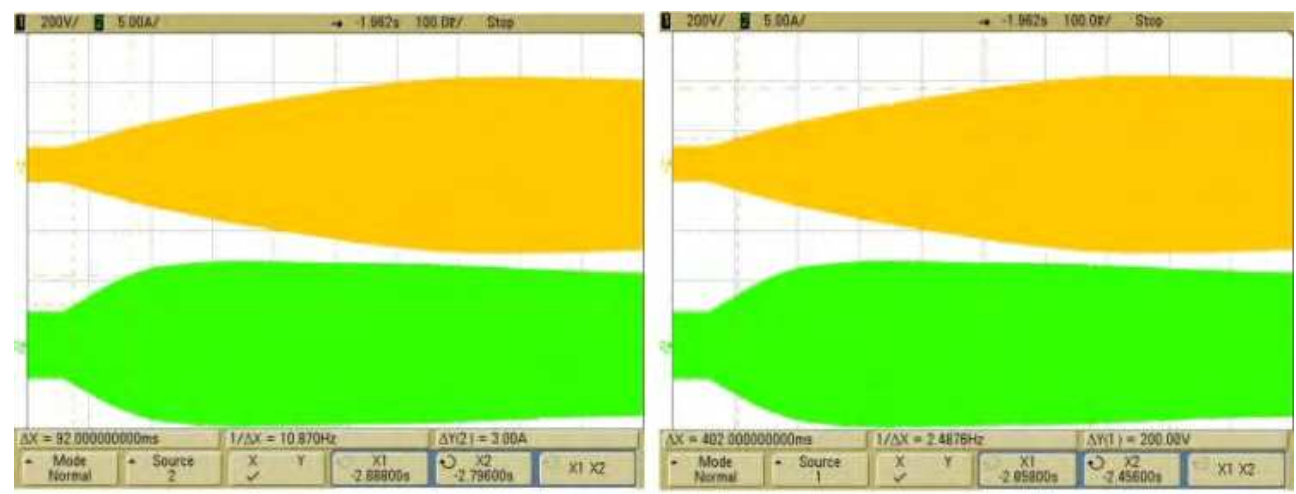

Fig. 18. 30V - 220V Step Response, $\mathrm{K}_{\mathrm{p}}=5, \mathrm{~K}_{\mathrm{I}}=750$, tc_min=1.5us showing Rise Time of (a) Bulb Current and (b) Bulb Voltage. 


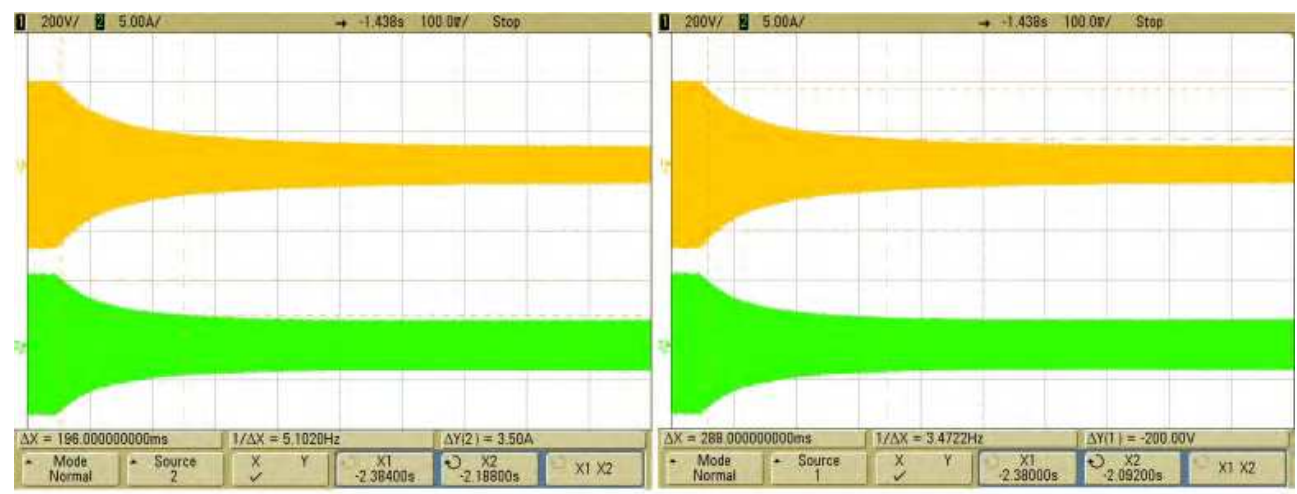

Fig. 19. 220V - 30V Step Response, $K_{p}=5, K_{I}=750$, tc_min=1.5us showing Fall Time of (a) Bulb Current and (b) Bulb Voltage.

achieved by reducing the minimum clamp time to $1.5 \mathrm{us}$ which increases the output current during the transient start up (beyond the maximum allowed steady state value shown in Fig. 13). In addition, PI gains can be increased for the pickup to yield a faster transient response. Here the $K_{p}$ and $K_{I}$ gains were increased to 5 and 750, respectively. Fig. 18 shows a step response of this system. It can be seen that both the current rise time and voltage rise time are much shorter $-92 \mathrm{~ms}$ and $402 \mathrm{~ms}$, respectively. Fig. 19 shows the step response from $220 \mathrm{~V}-30 \mathrm{~V}$. The fall times for both the current and voltage are also shorter as expected. However, even if the gain is increased significantly, the output voltage response does not have a considerable change as it is dominated by the low dynamic resistance of the bulb.

\subsection{Electric vehicle charging application using the parallel AC processing pickup}

An AC processing pickup with cascaded rectifier is also of interest in order to produce a controlled DC output. Although such a circuit performs a similar task (producing a controllable DC) to that of a traditional pickup that utilizes decoupling (or shorting) control (Boys et al., 2000) - it has several advantages. If a decoupling controller is used in applications with large variations in coupling, an inefficient method of overrating circuit devices is required. Because the coupling can change over a wide range, the short circuit current also changes significantly. Components like the DC inductor, the shorting switch and the rectifier have to be rated for the highest short circuit current condition while normally operating at lower currents. Moreover, since the short circuit current of the parallel resonant tank is constantly flowing through the switch, this causes constant on state losses in the switch which lowers efficiency. This is particularly evident in systems whose coupling coefficient can change by over $100 \%$ (Wang et al., 2005). To design such a system, the minimum coupling coefficient must be assumed in order to ensure that the minimum current is enough to satisfy the power transfer required. However, under maximum coupling conditions the short circuit current may be as much as $100 \%$ larger than that required under normal operation, which means all of the components have to be chosen such that they will operate safely at $200 \%$ of "rated" current. This inevitably reduces efficiency and increases cost. Although primary side control could be used to lower the track current and therefore the coupled voltage, feedback signals such as output voltage and current of the secondary pickup are then required to be sent to the primary converter via a 
wireless communication channel. This approach is suited to applications with only one pickup, given any action on the primary side affects all coupled receivers, however the system operation will then also inevitably depend on the reliability of the communication system which is a common source of problems. On the other hand, the AC processing pickup directly controls the output current from the resonant circuit to the rectifier, consequently, no overrating is required in applications where coupling varies. This chapter proposes an IPT charger using the AC processing pickup and provides design guidelines for this new pickup design.

\subsubsection{Circuit operation}

The AC processing pickup described earlier can be directly cascaded with a rectifier. An alternative circuit topology that is more practical or has fewer components is shown in Fig. 20. The rectification is performed in this new circuit structure using back to back MOSFET's forming the AC switch. This has the advantage of eliminating the need for two additional diodes in the rectifier. In addition, this new circuit has a common ground reference on both the AC and DC side. This makes measurement of any voltage signal on the AC or DC side easier as the measurement circuitry does not need to be isolated. The DC inductor and capacitor acts as a filter network to produce the DC output.

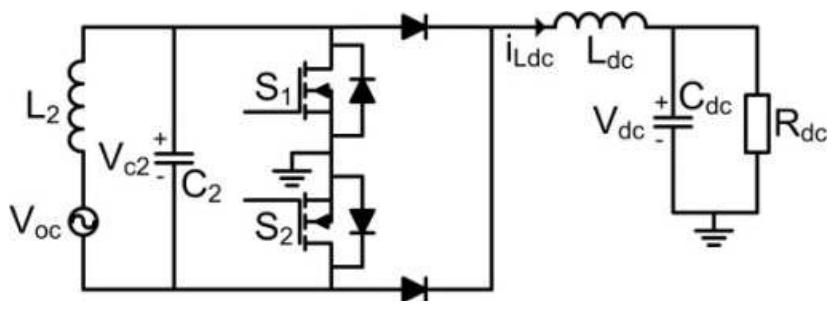

Fig. 20. An Parallel AC Processing Pickup Combined with Rectifier.

A design example for a $1 \mathrm{~kW}$ AC processing pickup is presented in Fig. 21. Here a PSOC microcontroller is again used to measure the output voltage and adjust the phase of the switch gate drive waveforms accordingly. Some key specifications are listed on the left side of Table 2 and the designed component values are presented on the right. The pickup regulates the output voltage $V_{d c}$ to a nominal $200 \mathrm{~V}$ when the load varies from $40 \Omega$ to open circuit. In addition, the coupling coefficient can change by more than $100 \%$ when the height between the primary and secondary pads changes from $45 \mathrm{~mm}$ to $90 \mathrm{~mm}$ which is the nominal operating range for the chosen pad (Budhia et al., 2009). The primary and secondary IPT pad has a circular structure shown in Fig. 22. Dimensions of both pads are exactly identical and each pad has 8 pieces of ferrite with 12 turns. The variation in coupling with respect to height is shown in Fig. 23(a). It can be seen that the coupling factor changes from $0.16-0.37$ as the distance between them varies from $45 \mathrm{~mm}-90 \mathrm{~mm}$. In addition, the variation in the inductance of the pads is shown in Fig. 23(b). The inductance of the pickup is $72.4 \mu \mathrm{H}$ and its value changes by $2.7 \%$ as the pad alignment changes. The designed $a$ value was calculated to be 0.87 in (Wu et al., 2011b), however the exact capacitance value of $206.5 \mathrm{nF}$ was not available. To be conservative, an $a$ value of 0.81 was chosen which gives a capacitance value of $192 \mathrm{nF}$. The minimum $V_{o c}$, calculated using the equation in (Wu et al., $2011 \mathrm{~b}$ ), is $77.12 \mathrm{~V}$ and the measured value is $78 \mathrm{~V}$ when $k=0.16$. As discussed in (Wu et al., 
2011b), the DC inductance is chosen to be 10 times higher than the minimum DC inductance $\left(L_{d c m i n}\right)$ while still maintaining appropriate switch ratings.
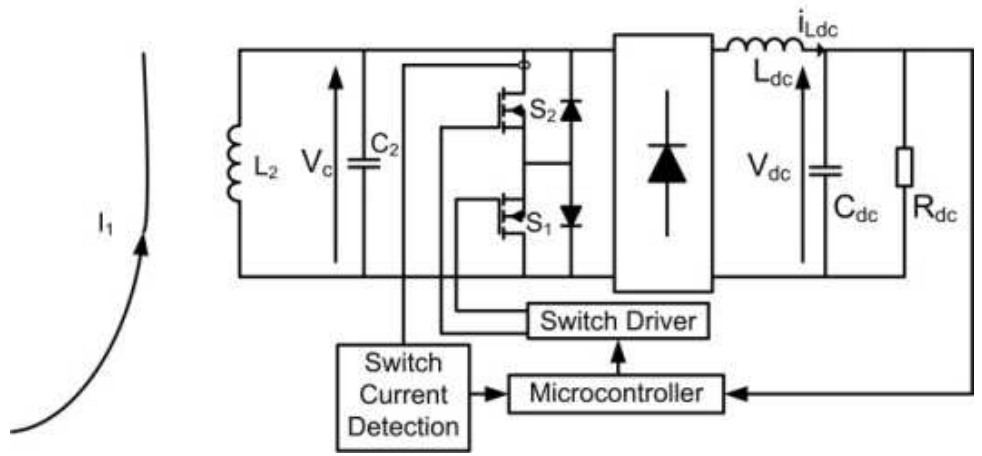

Fig. 21. Block Diagram of the AC Processing Pickup for EV Charger.

\begin{tabular}{|l|l|l|l|}
\hline Spec. Parameters & Values & Design Parameters & Values \\
\hline$k$ & $0.16-0.37$ & $\left(V_{\text {oc }}\right)_{\text {min }}$ & $78 \mathrm{~V}$ \\
\hline$P_{\text {out }}$ & $1 \mathrm{~kW}$ & $\left(I_{s c}\right)_{\text {min }}$ & $4.5 \mathrm{~A}$ \\
\hline$V_{d c}$ & $200 \mathrm{~V}$ & $a$ & 0.87 \\
\hline$R_{d c}$ & $40 \Omega-\infty \Omega$ & $g_{L}$ & 1.03 \\
\hline$I_{1}$ & $29.2 \mathrm{~A}$ & $g_{c}$ & 0.99 \\
\hline$F$ & $38.4 \mathrm{kHz}$ & $C_{2}$ & $192 \mathrm{nF}$ \\
\hline$L_{0}$ & $72.4 \mathrm{uH}$ & $L_{d c}$ & $540 \mathrm{uF}$ \\
\hline$C_{0}$ & $237.3 \mathrm{nF}$ & $C_{d c}$ & $1 \mathrm{mF}$ \\
\hline$L_{2 \mathrm{e}} / L_{0}$ & 0.02695 & & \\
\hline$C_{2 \mathrm{e}} / C_{0}$ & 0.1 & & \\
\hline
\end{tabular}

Table 2. Steady State Design Parameters for EV charging system.

All dimensions in $\mathrm{mm}$
A 30
Ferrite Width
B 118
C 10
D 238
Ferrite Length
E 420
Ring Thickness
Coil Diameter
Pad Thickness 25
Coil: 12 Turns

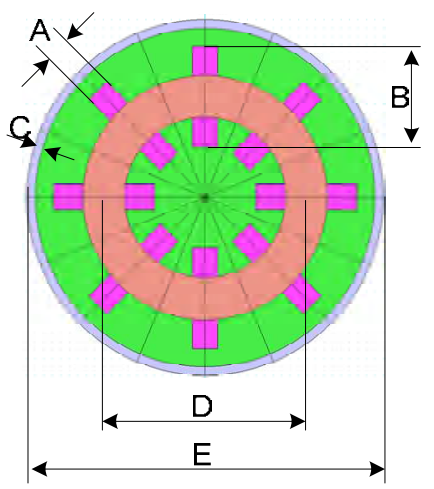

Fig. 22. EV Charger Pad Layout. 
For the practical system, the output voltage vs. clamp time is shown in Fig. 24. Measurements in blue show the output voltages when operating at a distance $d=90 \mathrm{~mm}$ with a coupling coefficient $k=0.16$. Similarly, the measurements in red show the output voltages when operating at a coupling coefficient $k=0.37$ with an air gap distance $d=45 \mathrm{~mm}$. As shown, the majority of the output voltage range can be achieved using a clamp time range of between 1-6 $\mu \mathrm{s}$. Since the theoretical control range for this $38.4 \mathrm{kHz}$ IPT system would be 013us, this control range is feasible and not too sensitive. To regulate the output voltage at $200 \mathrm{~V}$, the controller is required to measure the output voltage and vary the clamp time accordingly.
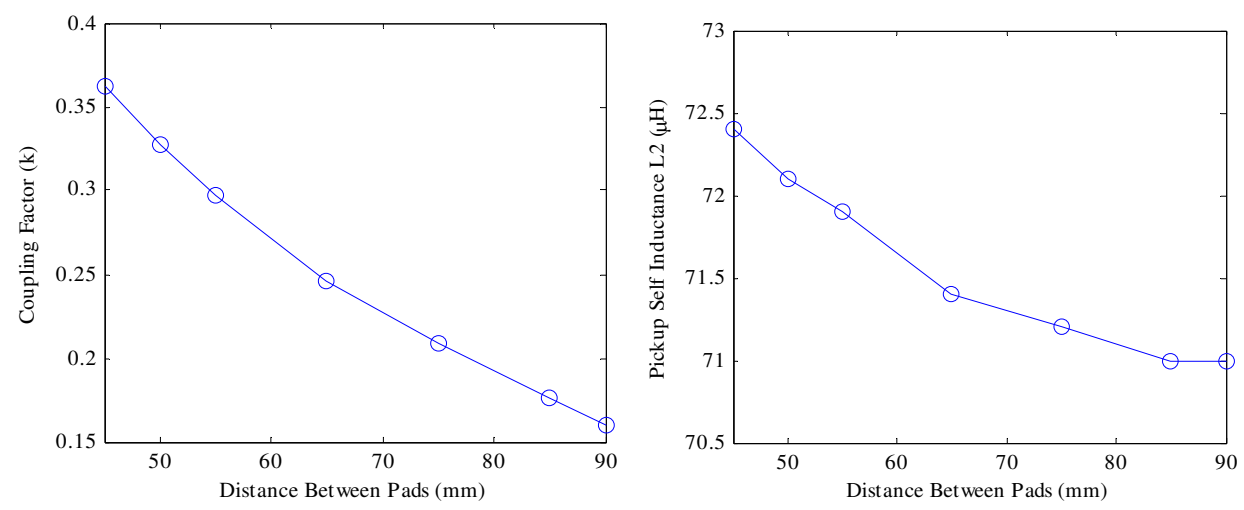

Fig. 23. (a) Coupling Factor vs. Distance Between Pads and (b) Pickup Inductance vs. Distance Between Pads.

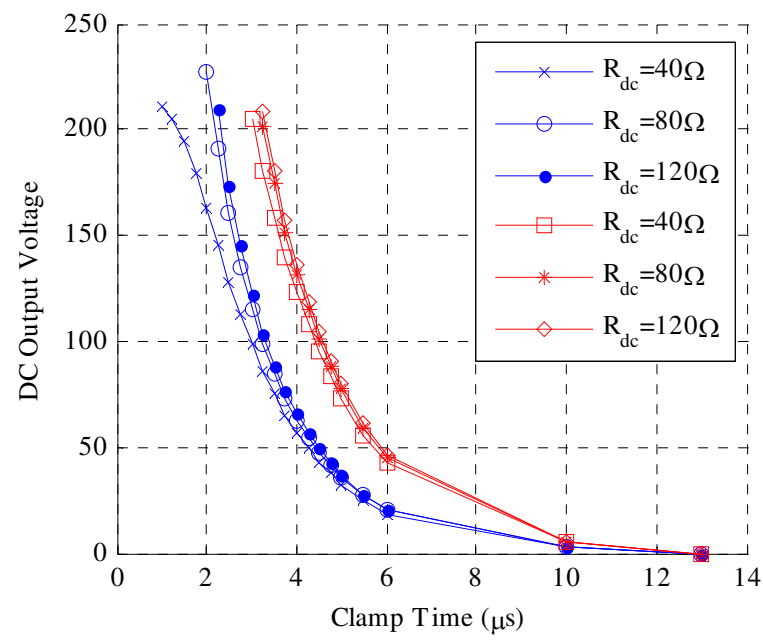

Fig. 24. Output Voltage Characteristics for Open Loop Controller.

A closed loop system was built based on the block diagram shown in Fig. 25. The output voltage is regulated to a desired reference using a simple PI controller to adjust the clamp 
time as shown in Fig. 25. The reference voltage can be set by a PC using serial communication. The capacitor voltage phase is measured using a detection block within the chosen microprocessor and is computed when the current starts to flow through the AC switch. A phase modulator block within the PSOC controls the phase between the output gate drive signals with respect to the phase of the capacitor voltage. Ideally this system provides a constant output voltage irrespective of coupling and load conditions. Since the change in pad inductance is inherently linked with coupling, only coupling variations are of interest as they include inductance variations.

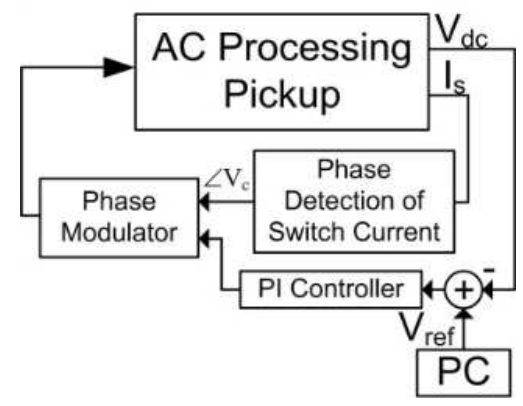

Fig. 25. EV Charging Controller Block Diagram.

Fig. 26 shows the circuit waveforms when the output voltage is regulated to $200 \mathrm{~V}$ at $k=0.16$ (or $d=90 \mathrm{~mm}$ ) for rated, $50 \%$ and $10 \%$ load, respectively. The waveforms are the resonant capacitor voltage, inductor current, DC inductor current and synchronization signal from the switch current detection block. Note that, the switch current detection inverts the logic which is inverted again at the output of the gate driver. Similarly, Fig. 27 shows the circuit waveforms when the output voltage is regulated to $200 \mathrm{~V}$ at $k=0.37$ (or $\mathrm{d}=45 \mathrm{~mm}$ ) for rated, $50 \%$ and $10 \%$ load, respectively. For the more tightly coupled system of $k=0.37$, the resonant inductor current is higher as the short circuit current in the pickup inductor is higher. In addition, the peak capacitor (or switch) voltage is also higher. This is because a higher clamp time is needed for the higher coupling condition to regulate the output at 200V. The measured result matches the results in (Wu et al., 2011b). Consequently, a higher clamp time for the same regulated output voltage results in higher peak voltages across the switches as identified in (Wu et al., 2011b). Notably the peak switch voltage does not exceed 450V which is half of the ratings of the physical devices chosen.

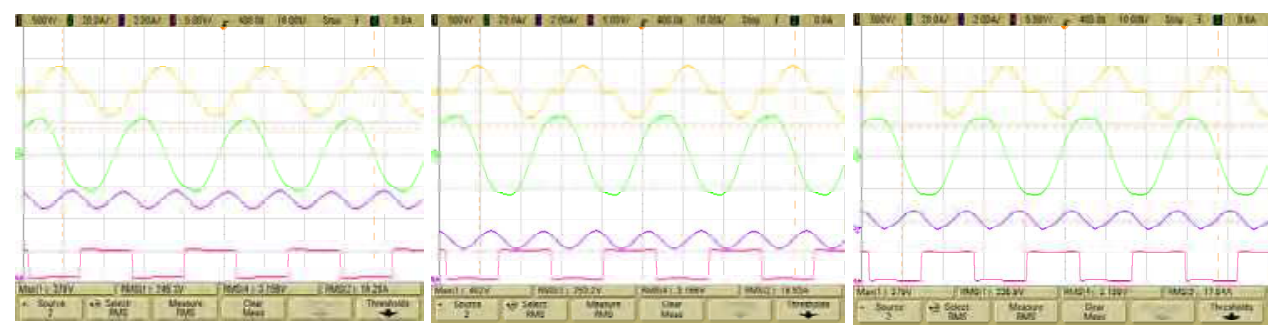

Fig. 26. Measured Waveforms at $200 \mathrm{~V}$ output with $\mathrm{k}=0.16$ for (a) Rated Load, (b) $50 \%$ Load and (c) $10 \%$ Load. 


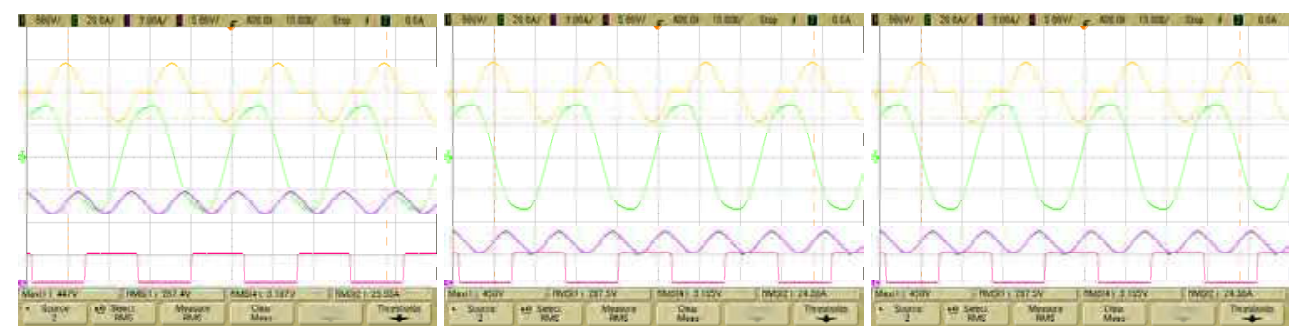

Fig. 27. Measured Waveforms at $200 \mathrm{~V}$ output with $\mathrm{k}=0.37$ for (a) Rated Load, (b) $50 \%$ Load and (c) $10 \%$ Load.

The measured output voltage under different operating conditions is shown in Fig. 28. Here, the circuit is tested over a wide range of coupling and load conditions. It can be seen that when the coupling and load resistance are higher than the designed minimum values specified (i.e. $k>0.16$ and $R_{L}>40 \Omega$ ), the output voltage can be regulated at $200 \mathrm{~V}$. However, if a higher load is used (i.e. $R_{L}<40 \Omega$ ), the output voltage drops below $200 \mathrm{~V}$ as the minimum clamp time will not be able to produce enough output current to sustain the voltage. Similarly, when $k<0.14$, the output voltage also drops below $200 \mathrm{~V}$.

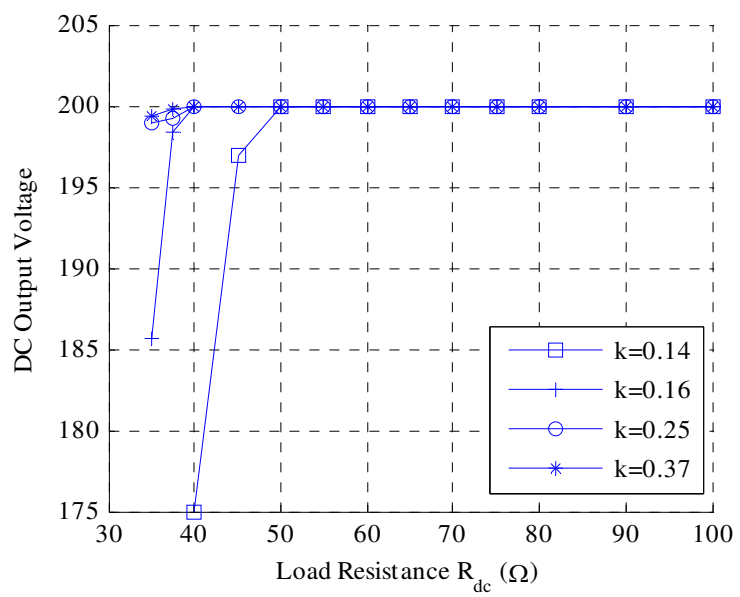

Fig. 28. Output Voltage under Different Circuit Conditions.

The measured efficiency of the secondary AC processing pickup alone is shown in Fig. 29(a). This measurement includes all the losses in the secondary pickup controller and neglects both the losses in the primary converter and the pickup pads. The efficiency of the secondary pickup electronics is as high as $97 \%$ when outputting $1 \mathrm{~kW}$ of controlled output power. As expected the efficiency decreases at lighter loads but as noted there is a point where it drops to a local minimum. This is mainly because the conduction losses in the AC switch are increased as the RMS current in these switches gets higher with increasing clamp time. At much lighter loads, the switch loss decreases because the overall resonant current in the parallel LC network is much lower. The DC-DC efficiency for the IPT system was measured and shown in Fig. 29(b). The efficiency is taken by measuring and comparing the 
DC input power to the primary LCL configured power supply used here and the DC output power to the load. As shown, the efficiency drops off at higher coupling conditions because the AC processing pickup reflects higher reactive VAR's back into the primary converter causing more conduction losses in both the LCL network and the H-bridge, but is between $73-83 \%$ at rated power, depending on the coupling condition.
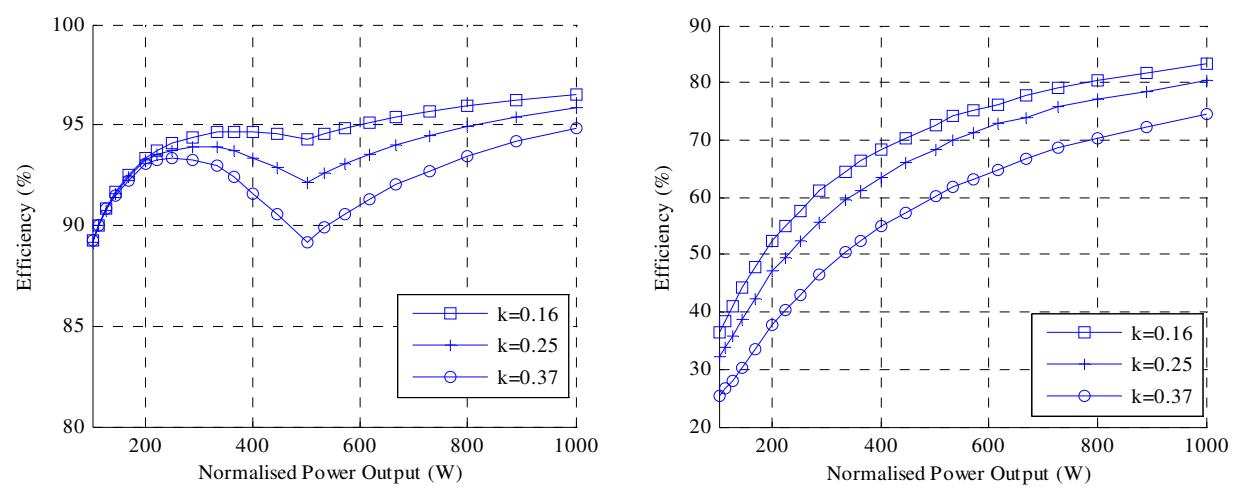

Fig. 29. (a) Efficiency of Parallel AC Processing Pickup, (b) Efficiency of Whole IPT System.

\section{Series AC processing pickups}

The series AC processing pickup is similar to the parallel AC processing controller described in earlier sections and most of its properties are duals or opposites. As expected it operates as a controllable voltage source and similar to other series IPT pickup designs, it can be very efficient when powering high current low-voltage loads. This section introduces the use of an AC switch operating under Zero-Current-Switching (ZCS) conditions to regulate the output voltage directly for a series AC processing pickup. This topology can produce a high frequency controlled $\mathrm{AC}$ voltage source which is ideal for incandescent lamps where the resistance rises as it warms up. When a rectifier is added to the AC output, the circuit can control the output DC voltage. This modified topology eliminates the need for an extra buck converter stage, improves efficiency and reduces cost. In addition, the circuit has the ability to control and eliminate the transient inrush current during start up ( $\mathrm{Wu}$ et al., 2011c). Preliminary experimental results show that the pickup regulator operates with high efficiency. Fig. 30 shows a traditional series tuned pickup with a buck converter output stage. The pickup stage comprises a series resonant tank, a bridge rectifier and a DC filter capacitor. The buck converter stage includes the switch, the filter inductor and capacitor, and the flywheel diode. The buck converter is used to regulate the output voltage to a desired voltage equal to or less than the rectified open circuit voltage of the pickup. It also protects the circuit if the load is a short circuit. Although there are many advantages to the series compensated pickup with a buck converter, it is not ideal because of the large number of components required in the circuit. In addition, the hard switching operations in the buck converter reduce efficiency and generate more EMI.

The new AC processing pickup proposed in this chapter can also generate a controlled DC voltage, like the series compensated pickup with a buck converter, however the overall 


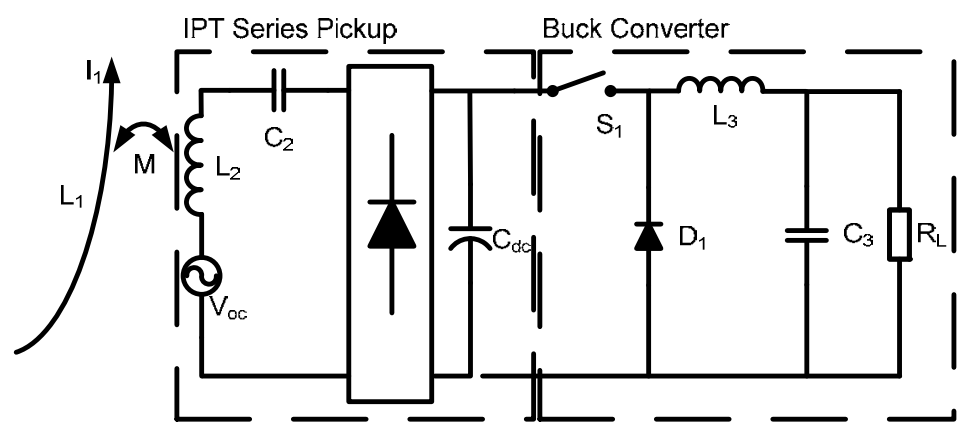

Fig. 30. A series compensated pickup with a buck converter.

circuit requires less components and the efficiency can be higher than that of the traditional circuit as it has soft switching operation, with only one conversion stage.

\subsection{Circuit operation}

The series AC processing pickup is shown in Fig. 31 with an AC output voltage $V_{R 2}$. Capacitor $C_{2}$ is tuned to inductor $L_{2}$ at the frequency of the primary track current $I_{1}$ to form a series resonant tank. For simplicity, switch $S_{1}$ is drawn as an ideal AC switch and is the basis for controlling the output voltage.

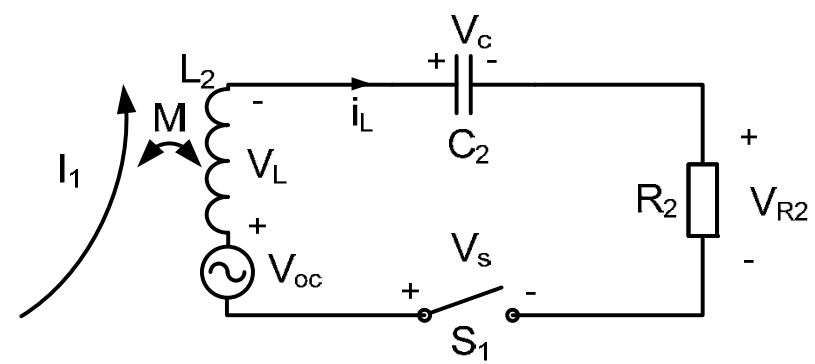

Fig. 31. The Series AC Processing Pickup.

By controlling the switching action of the AC switch, a phase shift $\phi$ will be generated between the open circuit voltage and the inductor current waveform as shown in Fig. 32 . Since the power sourced from $V_{o c}$ is directly proportional to the phase shift $\phi$ between the voltage and the current, the output power will be directly controlled if the conversion network is assumed to have negligible losses. Hence, by controlling the phase shift $\phi$, the output power is controlled.

\subsection{Pickup characteristics}

The analysis of the series AC processing pickup is very similar to the parallel and can be found in (Wu et al., 2011c). In this section, the operating characteristics of the series AC processing pickup are presented in comparison to the parallel AC processing pickup. The output current (or inductor current) characteristics of the series topology are shown in Fig. 33(a) for different values of $Q_{20}$ or load conditions. The normalized output current is defined 


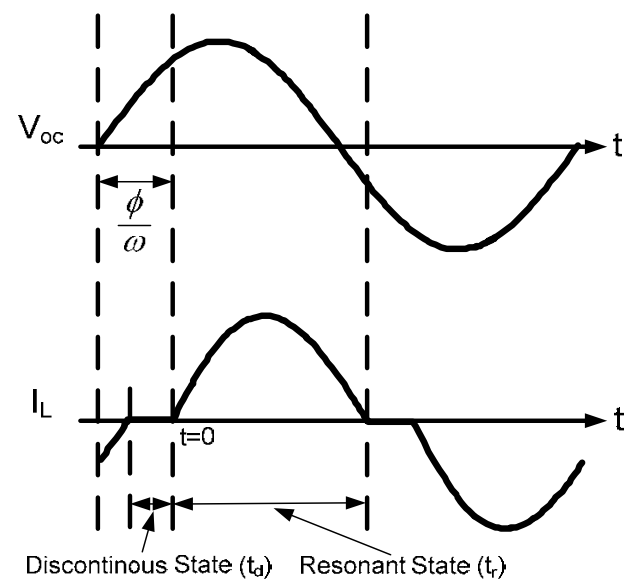

Fig. 32. Waveform showing Two Operating States for Series AC Processing Pickup.

as the ratio of the output current over the short circuit current. For the series AC processing pickup, the output current is dependent on both phase delay $\phi$ and $Q_{20}$. The normalized output current can be controlled from a maximum value (or $Q_{20}$ ) to zero as $\phi$ changes for all load conditions. In comparison, for the parallel AC processing pickup, the output current is mostly dependent on $\phi$ and marginally dependent on $Q_{20}$.
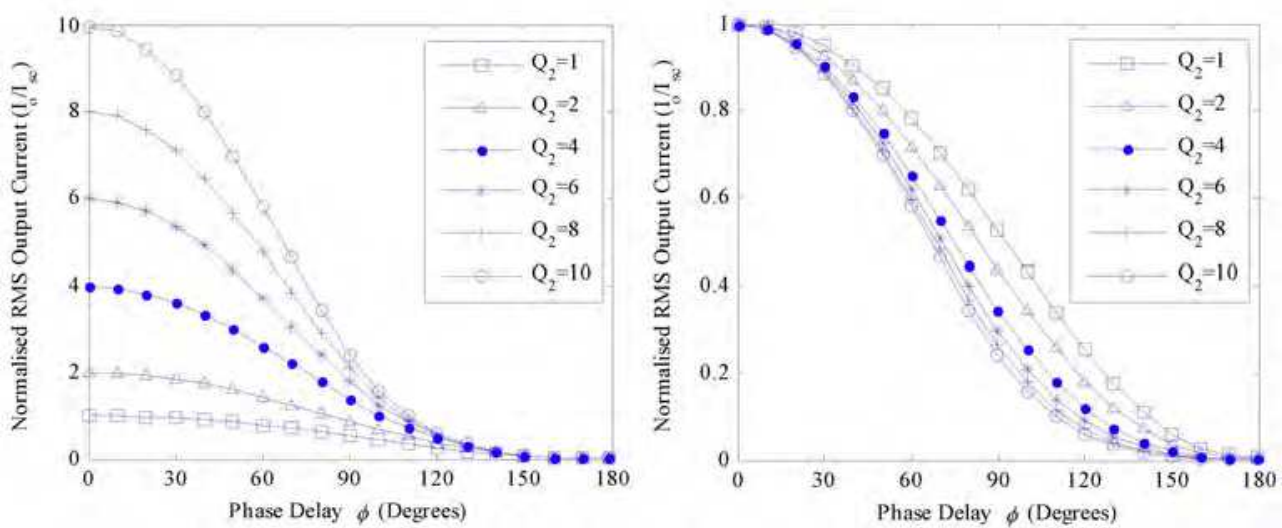

Fig. 33. Normalized RMS Output Current vs. Phase Delay $\phi$ for (a) Series and (b) Parallel.

The output voltage-current characteristic is shown in Fig. 34(a) for the series topology. The voltage source behaviour is demonstrated as the output voltage stays approximately constant for a given phase delay irrespective of output current as long as the output current is reasonably high. Similarly, the parallel AC processing pickup current-voltage characteristic, shown in Fig. 34(b), appears as a controlled current source. In applications where high currents are required for a short amount of time, the voltage source characteristic is particularly useful. If a parallel topology is used in such applications, it is usually more costly and inefficient to overrate the inductor coil in the parallel AC processing 
pickup to meet this demand. As previously noted, the series AC processing pickup will give rise to significant advantages in the overall system, as the output voltage can be controlled to any value below the open circuit voltage without the need of an extra buck converter after the pickup (shown in Fig. 30). This eliminates both the losses of an extra DC-DC conversion stage and the need for a costly DC inductor used in the buck converter.
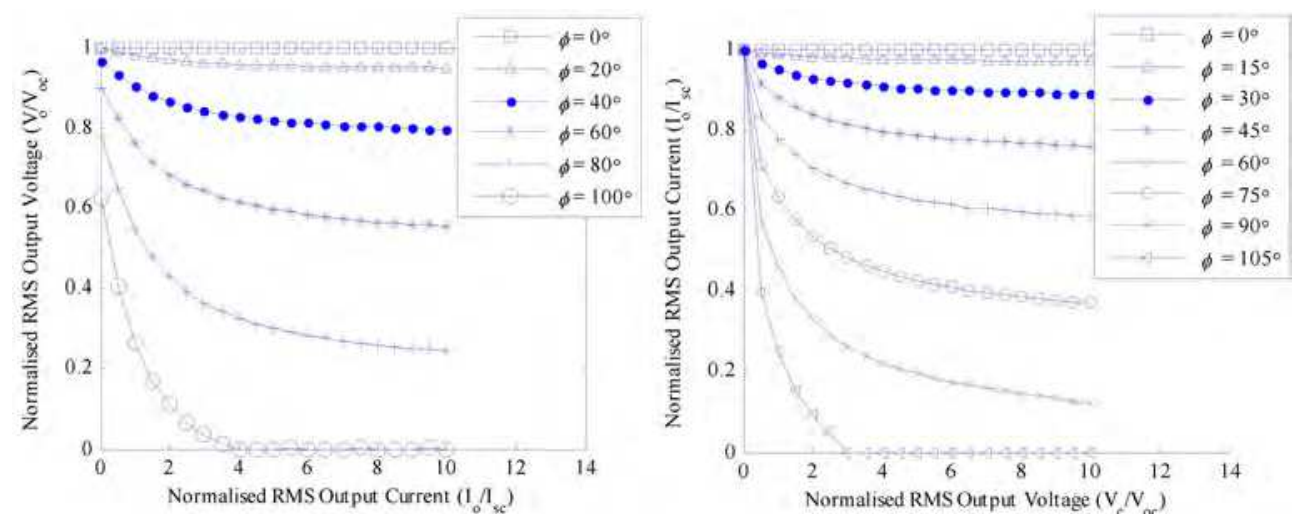

Fig. 34. Pickup Output Characteristics showing (a) Series and (b) Parallel.

\subsection{Discussion and experimental results}

A series AC processing pickup as described above was constructed with parameters in $(\mathrm{Wu}$ et al., 2011c). Fig. 35 shows the circuit waveforms for this series AC processing pickup at $100 \%, 50 \%$ and $20 \%$ power when $\phi$ is set to $0^{\circ}, 58^{\circ}$, and $85^{\circ}$, respectively. It shows the various operating waveforms: inductor current, capacitor voltage, inductor voltage and switch voltage. The inductor current and capacitor voltage are both sinusoidal having low distortion at $100 \%$ power. The small voltage overshoots across the switch result from snubber oscillations as discussed in ( $\mathrm{Wu}$ et al., 2011c). The measurements as shown have excellent correlation with analytically calculated waveforms in (Wu et al., 2011c) with amplitudes that are within $10 \%$ of the calculated values. Since the series AC processing pickup has an $\mathrm{AC}$ voltage source property, it can be used to drive incandescent lights.

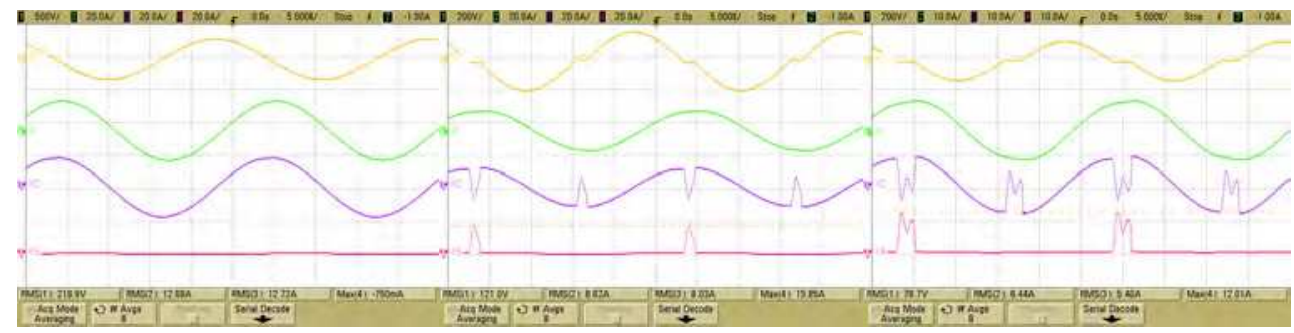

Fig. 35. Measured Waveforms for (a) 100\% power, (b) 50\% power and (c) $20 \%$ power with light bulb load.

An efficiency vs. output power plot is shown in Fig. 36(a) for the series AC processing pickup outputting a controlled $\mathrm{AC}$ voltage to a $6 \Omega$ load. In addition, the efficiency of the 
overall system including the AC processing pickup with rectifier outputting controlled DC to an $8 \Omega$ load is also plotted. The overall IPT system efficiency is determined using measurements of the DC input power to an LCL primary converter used as the IPT source, through to the AC output power from the secondary pickup. Similarly, the pickup efficiency is calculated using the AC input power delivered by the open circuit voltage source $\left(V_{o c}\right)$ and the AC output power from the secondary pickup. The $V_{o c}$ source is only present in a transformer coupling model and cannot be directly measured while the circuit is in operation. As such, an extra coil $L_{4}$ is used to estimate the actual phase and magnitude of $V_{o c}$. This method was found to be an accurate technique for measuring the input power given by:

$$
P_{\text {in }}=\frac{\omega}{2 \pi} \int_{0}^{2 \pi / \omega} V_{o c}(t) I_{L}(t) d t
$$

The pickup efficiency measurement neglects the supply (LCL converter) power losses and gives a more meaningful measure of the conversion efficiency of the pickup itself. The DC efficiency is measured with the losses in the rectifier taken into account. The efficiency of the pickup remains above $91 \%$ when the output power is more than $100 \mathrm{~W}$ to the AC load. With a $1.2 \mathrm{~kW}$ load, the efficiency of the series AC processing pickup and the overall IPT system can reach as high as $93 \%$ and $84 \%$, respectively when outputting either controlled AC or DC voltage. A breakdown of the power loss measurements for the series AC processing pickup is shown in Fig. 36(b). The switch losses, pickup inductor coil and core losses, capacitor ESR losses, snubber losses, rectifier losses and stray losses are all accounted for individually. The stray loss includes copper losses of the PCB tracks and connectors. At full power there are $35 \mathrm{~W}$ of loss in the switch giving a 3\% reduction in efficiency compared to a traditional series tuned pickup without a buck converter. In a cascaded buck converter, the efficiency would be lower due to additional losses in the DC inductor. At lower power levels, the long discontinuous parts in the resonant waveforms as a result of the controlled switch operation (Fig. 32) decrease the losses in all components and the efficiency of the overall pickup is maintained relatively high. For the harmonic components generated by the discontinuous
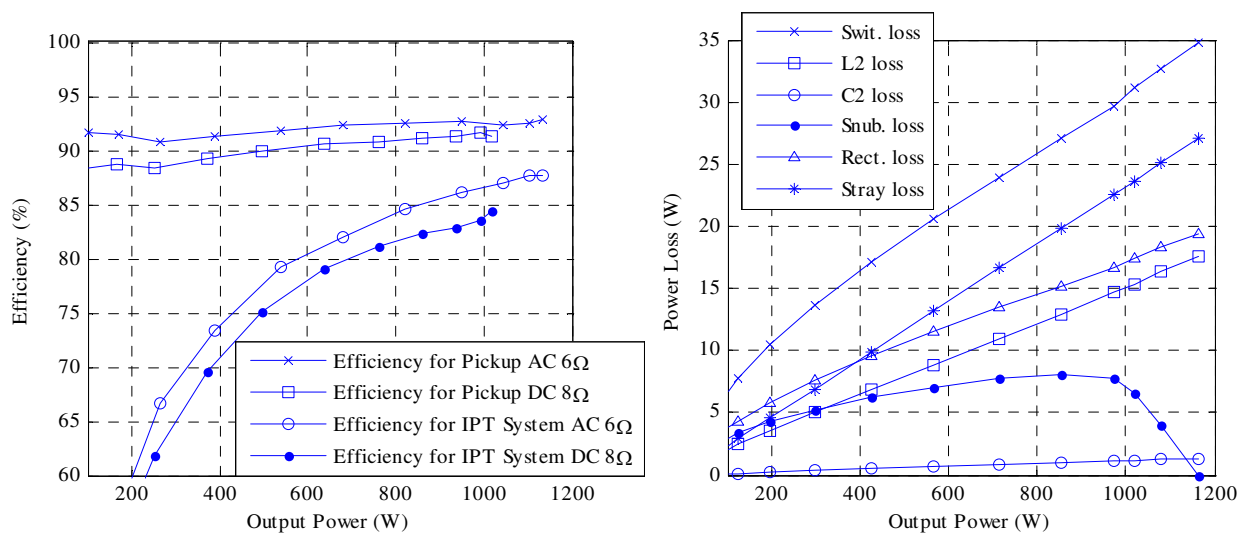

Fig. 36. (a) Efficiency vs. Output Power and (b) Losses vs. Output Power. 
control of the AC processing method shown in (Wu et al., 2011c), there are pickup inductor losses due to skin effect. However, the magnitude of the skin effect losses is only $10 \%$ of the maximum losses of the fundamental component for this $20 \mathrm{kHz}$ IPT system.

\section{Conclusions}

This chapter has presented two new IPT pickups which have significant advantages compared to traditional pickups that use AC-DC-AC conversion topologies for producing a controllable AC output voltage. Both simple AC processing pickup controllers described can provide controlled AC power over a wide resistive load range. In addition, the simple pickup circuitry has advantages in terms of increasing system efficiency and reducing the pickup size. The fundamental properties and design equations of both the series and parallel tuned AC processing pickup have been investigated.

\section{References}

Wu, H.H.; Covic, G.A.; Boys, J.T.; Ren, S. \& Hu, A.P. (2009a). An AC Processing Pickup for IPT Systems. Proceedings of the IEEE Energy Conversion Congress and Expo, ISBN 9781-4244-2893-9, San Jose, USA, September 2009

Wu, H.H.; Covic, G.A. \& Boys, J.T. (2010). An AC Processing Pickup for IPT Systems. IEEE Transactions on Power Electronics, Vol. 25, No. 5, (2010), pp. 1275-1284, ISSN 0885-8993

Boys, J.T.; Covic, G.A. \& Green, A.W. (2000). Stability and Control of Inductively Coupled Power Transfer Systems. IEE Proceedings on Electric Power Applications, Vol. 147, No. 1, (2000), pp. 37-43, ISSN 1350-2352

Elliot, G.A.J. ; Covic, G.A. ; Kacprzak, D. \& Boys, J.T. (2006). A New Concept: Asymmetrical Pick-ups for Inductively Coupled Power Transfer Monorail Systems. IEEE Transactions on Magnetics, Vol. 42, No. 10, (2006), pp. 3389-3391, ISSN 0018-9464

Wu, H.H.; Covic, G.A.; Boys, J.T \& Ren, S. (2009b). Analysis and Design of an AC Processing Pickup for IPT Systems. Proceedings of the 35th Annual Conference of IEEE Industrial Electronics, ISBN 978-1-4244-4648-3, Porto, Portugal, November 2009.

Wu, H.H.; Covic, G.A.; Boys, J.T. \& Robertson, D. (2011a). A Practical 1.2kW Inductive Power Transfer Lighting System using AC Processing Controllers. To be published on Proceedings of the IEEE Conference on Industrial Electronics and Applications, Beijing, China, June 2011

Wang, C.-S.; Stielau O.H. \& Covic, G.A. (2005). Design Considerations for a Contactless Electric Vehicle Battery Charger. IEEE Transactions on Industrial Electronics, Vol. 52, No. 5, (2005), pp. 1308-1314, ISSN 0278-0046

Budhia, M.; Covic, G.A. \& Boys, J.T. (2009). Design and Optimisation of Magnetic Structures for Lumped Inductive Power Transfer systems. Proceedings of the IEEE Energy Conversion Congress and Expo, ISBN 978-1-4244-2893-9, San Jose, USA, September 2009

Wu, H.H.; Covic, G.A. \& Boys, J.T. (2011b). A 1kW Inductive Charging System using AC Processing Pickups. To be published on Proceedings of the IEEE Conference on Industrial Electronics and Applications, Beijing, China, June 2011

Wu, H.H.; Covic, G.A.; Boys, J.T. \& Robertson, D. (2011c). A Series Tuned Inductive Power Transfer Pickup with a Controllable AC Voltage Output. IEEE Transactions on Power Electronics, Vol. 26, No. 1, (2011), pp. 98-109, ISSN 0885-8993 


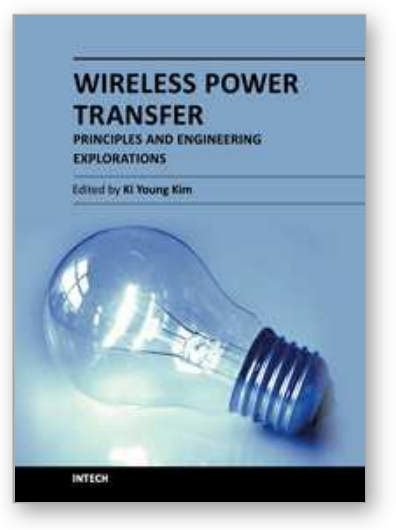

\author{
Wireless Power Transfer - Principles and Engineering Explorations \\ Edited by Dr. Ki Young Kim
}

ISBN 978-953-307-874-8

Hard cover, 272 pages

Publisher InTech

Published online 25, January, 2012

Published in print edition January, 2012

The title of this book, Wireless Power Transfer: Principles and Engineering Explorations, encompasses theory and engineering technology, which are of interest for diverse classes of wireless power transfer. This book is a collection of contemporary research and developments in the area of wireless power transfer technology. It consists of 13 chapters that focus on interesting topics of wireless power links, and several system issues in which analytical methodologies, numerical simulation techniques, measurement techniques and methods, and applicable examples are investigated.

\title{
How to reference
}

In order to correctly reference this scholarly work, feel free to copy and paste the following:

Hunter Hanzhuo Wu, Grant Anthony Covic and John Talbot Boys (2012). AC Processing Controllers for IPT Systems, Wireless Power Transfer - Principles and Engineering Explorations, Dr. Ki Young Kim (Ed.), ISBN: 978-953-307-874-8, InTech, Available from: http://www.intechopen.com/books/wireless-power-transferprinciples-and-engineering-explorations/ac-processing-controllers-for-inductive-power-transfer-systems

\section{INTECH}

open science | open minds

\section{InTech Europe}

University Campus STeP Ri

Slavka Krautzeka 83/A

51000 Rijeka, Croatia

Phone: +385 (51) 770447

Fax: +385 (51) 686166

www.intechopen.com

\section{InTech China}

Unit 405, Office Block, Hotel Equatorial Shanghai

No.65, Yan An Road (West), Shanghai, 200040, China

中国上海市延安西路65号上海国际贵都大饭店办公楼405单元

Phone: +86-21-62489820

Fax: $+86-21-62489821$ 
(C) 2012 The Author(s). Licensee IntechOpen. This is an open access article distributed under the terms of the Creative Commons Attribution 3.0 License, which permits unrestricted use, distribution, and reproduction in any medium, provided the original work is properly cited. 